\title{
CAPACITY-EXPANSION PLANNING UNDER UNCERTAINTY IN THE ELECTRIC-UTILITY INDUSTRY
}

\author{
REPORT 3 \\ RFP El-78-R-01-6242 \\ (Phase - II) \\ Systemetrics, Inc. \\ P.O. Drawer S \\ Blacksburg, Virginia 24060
}

\author{
July 25,1980
}

\author{
Allen L. Soyster \\ Principal Investigator
}




\section{DISCLAIMER}

This report was prepared as an account of work sponsored by an agency of the United States Government. Neither the United States Government nor any agency Thereof, nor any of their employees, makes any warranty, express or implied, or assumes any legal liability or responsibility for the accuracy, completeness, or usefulness of any information, apparatus, product, or process disclosed, or represents that its use would not infringe privately owned rights. Reference herein to any specific commercial product, process, or service by trade name, trademark, manufacturer, or otherwise does not necessarily constitute or imply its endorsement, recommendation, or favoring by the United States Government or any agency thereof. The views and opinions of authors expressed herein do not necessarily state or reflect those of the United States Government or any agency thereof. 


\section{DISCLAIMER}

Portions of this document may be illegible in electronic image products. Images are produced from the best available original document. 
Table of Contents

Chapter

Page

PART I - BACKGROUND

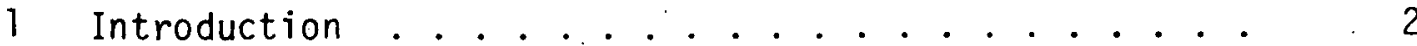

2 Least Cost Investment Models in the Electric Utility Industry

\section{PART I I--DECISION-MAKING AND UNCERTAINTY}

3 Uncertainty and the Behavior of the Firm . . . . . .

PART III--CAPACITY EXPANSION UNDER UNCERTAINTY

4 Sequential Uncertainty and Decision Analysis . . . .

5 Modelling Uncertainty in System Dynamics ........

6 Level of Reliability and Capacity Choices . . . . .

7 Probabilistic Reliability Standards and Capacity Expansion . . . . . . . . . . . . .

8 The Averch-Johns on Hypothesis Under Uncertainty

\section{PART IV--INDUSTRY PRACTICE}

9 Industry Implementation of Capacity

Planning Models

References

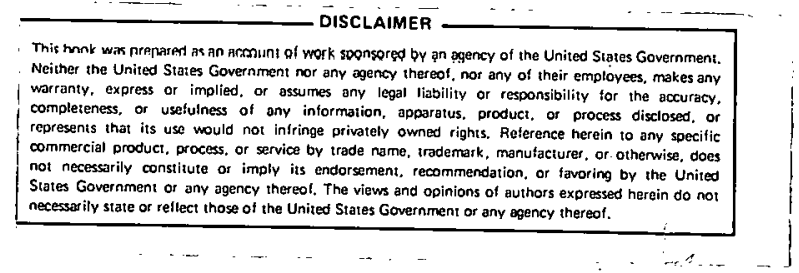


PART I--BACKGROUND 
Chapter 1

Introduction

This document represents the third and final report of the DOE project EI-78-R-01-6242 (Phase II) which is concerned wi th capacity expansion planning in the electric utility industry. The first two reports in the Phase II effort are:

--Literature Review on Capacity Expansion Under Uncertainty

--Some Observations on the Practice of Capacity Expansion in the Electric Utility Industry.

This third report basically represents a comparison between theory and practice of capacity expansion planning in the electric utility industry. The purpose of the comparison is to provide avenues for further exploration in utility decision-making. The focus of the Phase II study is upon the role of uncertainty in the decision-making process. (The Phase I effort was directed at modelling the Averch-Johnson theory of the regulated utility.)

This report is presented in four parts. In the first part a review of the often quoted Anderson [1] study is presented. Although. the investment models considered by Anderson are wholly of a deterministic nature, an understanding of the linear programs reviewed by Anderson is a necessary prerequisite for pursuing uncertainty extensions of process-oriented models. Furthermore, the Anderson paper has become a standard reference for capacity planning studies in the electric utility industry. 
The second part is comprised of a single chapter about uncertainty and the behavior of the firm. The chapter represents a review of the main theoretical results concerning the impact of output price uncertainty on the production decisions of the firm. For example, how does uncertainty about selling price for a competitive firm affect the "deterministic rule" of setting price equal to marginal cost?

The third part is a review of five different models of electric utility capacity planning under uncertainty. Each one represents a different methodology for explicitly incorporating uncertainty into the decision-making process. In Chapter 4 the so-called "over/under capacity" decision analysis scheme of Cazalet et al. [8], [9] is presented. In this case the uncertainty concerns future demand. Next, in Chapter 5 the system dynamics approach of Ford [13] and Stover, Hayward and Becker [31] is reviewed. Uncertainties affecting both supply and demand are integrated into the system dynamics framework. Bulk system generation reliability is the subject of Chapter 6 . In this chapter the approach by Telson [34], in which incremental capacity is added until marginal benefit equals marginal cost, is reviewed and compared with other similar studies. The next chapter is devoted to a review of recent work of Bloom [4], [5] and [6]. Bloom discusses how an overall capacity expansion problem can be decomposed into a separate investment and production problem. The advantage of the decomposition is that more realistic reliability constraints can be factored into the production problem. The final chapter in this 
third part of the report is about the Averch-Johnson hypothesis (which concerns an alleged over-capitalization bias) and uncertainty. Based upon a recent paper by Peles and Stein [25], it is shown that a regulated utility, subject to uncertainty, may actually "under-capitalize,," a result Peles and Stein termed the "anti A-J effect."

Part 4 is concerned with capacity planning models in practice. There are clearly two such models that have received widespread usage by the electric utility industry. The first of these is the WEIN Automatic System Planning (WASP) model developed at TVA and the other is Optimized Generation Planning (OGP) which is used by the General Electric Company. Chapter 9 provides a review and comparison of these two models along with some explanation as to why they have been implemented and other models have not. 


\section{Chapter 2 \\ Least Cost Investmeilt ilodels \\ in \\ Electricity Supply}

Overview

This chapter is devoted to a review of a single, much quoted paper by Anderson [1]. The paper, published in 1972, is mainly about a class of mathematical programming models originally formulated by Masse and Gibrat [21]: Although there have been several alternative mathematical programming formulations of capacity expansion in the electric utility industry, an understanding of Masse and Gibrat model is sufficient to characterize the general thrust of most contemporary process-oriented electric utility models. One of Anderson's chief contributions in the review of extension of Masse and Gibrat is his clear characterization of the specific assumptions, objectives, methods and shortcomings of Masse and Gibrat model. Anderson's summary of his own paper reads as follows:

This paper reviews models used in the electric supply industry for appraising investments, and presents some extensions. Quantities demander and the prices of inputs and outputs are assumed to be exogenous, and the models search for investments having the lowest costs. Optimization is over several time periods. Typical decision variables considered are: choice of fossil, nuclear, single- or multi-purpose hydro plant; locations of plants; directions of electrical energy transport (interconnection); timing of investments; replacement; and in all cases the optimiril mode of system operation (including hydro storage policy). These variables may be analyzed by linear, non-linear, and dynamic programming as well as other methods. 
As will be made clear subsequently, the general form of the Masse and Gibrat model is the linear program (2-1).

$$
\begin{array}{r}
\min c \cdot x+d \cdot y \\
A x+B y \leq b \\
x, y \geq 0
\end{array}
$$

Two general types of variables are defined: the $x$ vector represents alternative investment decisions and the $y$ vector represents operational decisions with $\mathrm{c}$ and $\mathrm{d}$ being the appropriate factor costs. Forecasted demand is included in the right-hand side vector b. Anderson summarizes several of the assumptions of Masse and.Gibrat as follows:

(1) Quantities demanded are assumed exogenous and the objective is always cost minimization.

(2) The formulation is completely deterministic.

(3) The formulation is time-dynamic over some finite horizon, a) though no consideration is given to any bias due to the finiteness of the planning horizon.

Since the output of the model is a plan for choosing alternative investments, as well as associated operating policies, the model is of the "capacity expansion" type. However, Anderson cautions the analyst that there are a number of important considerations beyond the realm of the economic model represented by $(2-1)$. Anderson says,

Use of one or more investment models is the first of several stages of the investment decision process. Engineering analys is of solutions follows and generally requires a revision of the solutions. The investment program finally selectedmust satisfy 
a number of engineering criteria regarding system stability, short-circuit performance, the control of watts, vars, and voltage, and the reserves and reliability of supply. The search for an investment program which satisfies engineering and economic criteria is an iterative, multi-disciplinary process.

It should also be pointed out that the Masse and Gibrat model that is described in the next section has been applied at both the level of the firm as well as at regionalized levels where utilities are represented in aggregate form. This contrast (and its implications for planning) is not emphasized by Anderson.

In [1] it is implicitly assumed that the model is for investment planning by an individual firm. For example, Anderson says,

Let the power capacity of any plant in the system be defined by $x_{j}, j$ denoted the type of plant (hydro, fossil, nuclear, etc.' $y^{\prime}$ and $v$ the vintage (year of commissioning).

Presumably; then, plant $j$ may be 400 megawatt coal plant commissioned in 1986 at, say, Altoona, Pennsylvania. At the regionalized level the model variable $x_{j v}$, in contrast, may be 4000 megawatts and would represent the aggregate coal capacity commissioned for the mid-Atlantic states in 1986 .

The validity of using the Masse and Gibrat linear programming model for planning capacity expansion at the firm level versus an aggregated regional level involves different sets of considerations. At the level of the firm the question is always raised whether the linear "returns to scale" is valid. In a linear program one must assume that unit capacity cost for plant type $j$ is $c_{j}$ and, hence, a one megawatt plant costs $1 \times c_{j}$ and a one-hundred megawatt plant costs 
$100 \times c_{j}$. In the aggregate form, questions about returns to scale can be cleverly dismissed (or disguised) by assuming that the 4000 megawatts of total coal capacity represents ten 400 megawatt plants. However, at this aggregate level it is somewhat difficult to defend the assumption that all utilities cooperate to minimize total costs for the region (which is implicit in the nature of the linear programming cost minimizing solution). This important question, not addressed by Anderson, will be further discussed in Chapter 9.

\section{Linear Program of Masse and Gibrat}

There are two basic classes of variables in the linear program of Masse and Gibrat [21]. The set $\left\{x_{j v}\right\}$ represents the capacity of plant $j$ commissioned in period $v$, while $\left\{u_{j v t}\right\}$ represents the power output in period $t$ from plant $j$ which is commissioned in period $v$. The linear programming objective is

$$
\sum_{v=1}^{T} \sum_{j=1}^{J} c_{j v} x_{j v}+\sum_{t=1}^{T} \sum_{v=-v}^{t} \sum_{j=1}^{J} \theta_{t} f_{j v t} u_{j v t}
$$

where $-V$ represents the age (vintage) of the oldest plant in the system, $c_{j v}$ is discounted capital cost of plant type $j$ in period $v, \theta_{t}$ is the width of the time period and $f_{j v t}$ is the discounted operating costs per unit of energy output.

There are three main classes of constraints:

(1) For each period t one must satisfy the demand for power.

(2) No unit can generate power above its peak availability.

(3) Certain margins of safety of supply over demand must be maintained. 
In algebraic terms these three classes are, respectively,

$$
\begin{array}{ll}
\sum_{j=1}^{J} \sum_{v=-v}^{t} u_{j v t} \geq Q_{t} & t=1,2, \ldots, T \\
0 \leq u_{j v t} \leq a_{j v} x_{j v} & j=1,2, \ldots, J \\
& v=-v, \ldots, t \\
& t=1,2, \ldots, T \\
\sum_{j=1}^{J} \sum_{v=-v}^{t} a_{j v} x_{j v} \geq(1+m) Q_{t} & t=1,2, \ldots, T
\end{array}
$$

where

$$
\begin{aligned}
Q_{t} & \equiv \text { power demand in period } t \\
a_{j v} & \equiv \text { availability of plant } j, \text { vintage } v \\
\hat{Q}_{t} & \equiv \text { expected peak demand in period } t \\
m & \equiv \text { reserve margin }
\end{aligned}
$$

To gain more realism, other constraints representing fuel consumption, special consideration for pondage hydro and pumped storage, the impact of transmission restrictions plus other extensions have been formulated and appended to $(2-3),(2-4)$ and $(2-5)$ by several authors. Although many of these constraints are clearly useful and interesting, we include only one further refinement of the linear program defined by $(2-2),(2-3),(2-4)$ and $(2-5)$, and this refinement deals with the so-called load-duration curve.

The load duration curve shown in Figure $2-1$ is discretized into $P$ vertical segments where for $p=1,2, \ldots, P, \theta_{p}$ represents the 


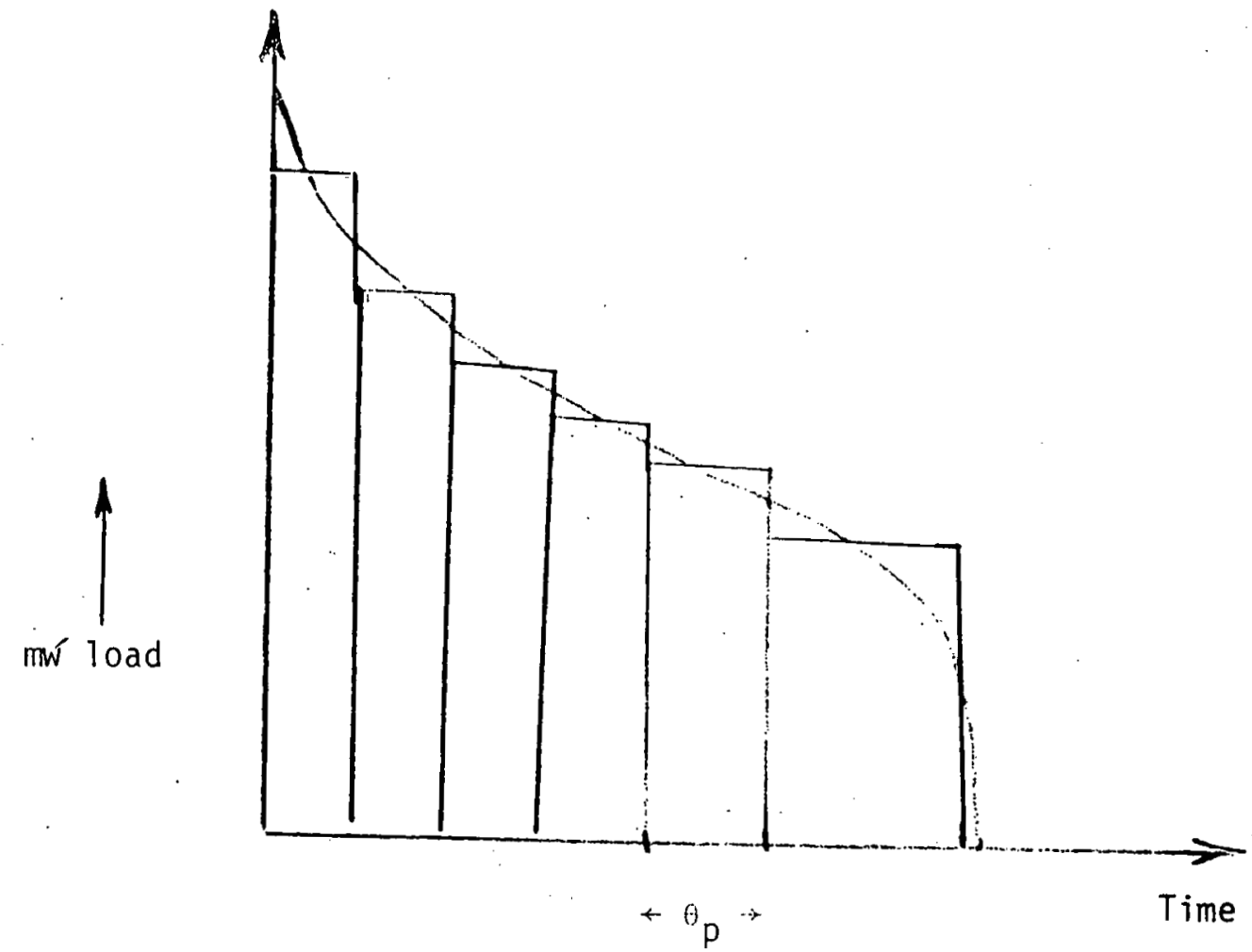

Figure 2-1

Discretized Load-Luration Curve

interval width. The fundamental point is that each period $t$ is not fully or appropriately represented by a single uniform load $Q_{t}$ as assumed in $(2-3)$. The uniform load $Q_{t}$ is replaced by $P$ loads, i.e., $\left(Q_{t]}, Q_{t 2}, \ldots . ., Q_{t p}\right)$ as suggested by the discretized load curve of Figure 2-1. Such a refinement means that the power output variables are quadruply subscripted $\left\{u_{j t v p}\right\}$ and the number of constraints in $(2-3)$ and $(2-4)$ are increased by a factor of $P$. The linear program which accounts for the shape of the load-duration curve is

$$
\begin{aligned}
& \min \sum_{v=1}^{T} \sum_{j=1}^{J} c_{j v} x_{j v}+\sum_{j=1}^{J} \sum_{t=1}^{T} \sum_{v=-v}^{t} \sum_{p=1}^{p} \theta_{t p} f_{j t v p} u_{j i v p} \\
& \sum_{j=1}^{J} \sum_{v=-v}^{t} u_{j t v p} \geq Q_{t p} . \quad \begin{array}{l}
t=1,2, .: . \\
p=1,2, . \cdot .
\end{array}
\end{aligned}
$$




$$
\begin{aligned}
& 0 \leq u_{j t v p} \leq a_{j v} x_{j v} \quad j=1,2, . ., J \\
& v=-v, \cdot ., t \\
& \mathrm{t}=1,2, \ldots . \mathrm{T} \\
& p=1 ; 2, \ldots ., P \\
& \sum_{j=1}^{J} \sum_{v=-v}^{t} a_{j v} x_{j v} \geq(1+m) \hat{Q}_{t} \quad t=1,2, \ldots ., T \\
& x_{j v} \geq 0 . \quad \begin{array}{l}
j=1,2, \ldots \cdot, j \\
v=-v, \cdot . \cdot T
\end{array}
\end{aligned}
$$

Implementation Strategies

In this section two alternative methods of solving (2-6) are described. The first method is nothing more than solving the linear program (2-6) in a normal, straightforward fashion. Furthermore, in view of this obvious strategy, why should any other strategy ever be considered? Anderson's explanation is as follows:

A difficulty with LP models of the above type is the large number of constraints encountered in any realistic formulation of a problem. . . . If there are on the average $20 \mathrm{plants}$ on the system, and we break the load duration curve into ten discrete intervals and take a 30 year period broken down into 6 5-year intervals, then we have about . . 1500 constraints in the problem.

Apparently, as recently as 1972 the problem size generated by realistic applications of (2-6). was considered rather 1 arge. Probiem size is one, but not the sole, reason why an alternative solution strategy is a decomposition of (2-6) into two different problems, namely, an investment problem and a production simulation problem. The key observation is that if the variahles $\left\{x_{j v}\right\}$ are somehow fixed in $(2-6)$, then the remaining problem is still a well-defined but 
substantially simpler linear program. In fact closer scrutiny reveals that the resulting "production" problem is

$$
\begin{aligned}
& \min \sum_{j=1}^{J} \sum_{t=1}^{T} \sum_{v=-v}^{t} \sum_{p=1}^{p} \theta_{t p} f_{j . t v p} u_{j t v p} \\
& \sum_{j=1}^{J} \sum_{v=-v}^{t} u_{j t v p} \geq Q_{t p} \quad \begin{array}{l}
t=1,2, \ldots, T \\
p=1,2, \ldots, P
\end{array} \\
& 0 \leq u_{j t v p} \leq a_{j v} \bar{x}_{j v} \quad \begin{array}{l}
j=1,2, \ldots, j \\
v=-v, \ldots, t
\end{array} \\
& t=1,2, \ldots, T \\
& p=1,2, \ldots, p
\end{aligned}
$$

where the last set of structural constraints are simply upper bounds on $\left\{u_{j t v p}\right\}$; the capacity variables $\left\{\bar{x}_{j y}\right\}$ are fixed in $(2-6)$.

Furthermore, the "production problem" (2-7) can be decomposed even further. There are in fact TP separate and independent i inear programs embodied in (2-7). For each $t=1,2, \ldots, T$ and each $p=1,2, \ldots, p$, say $\bar{t}$ and $\bar{p}$, one has

$$
\begin{aligned}
& \min \sum_{j=1}^{J} \sum_{v=-v}^{\bar{E}} \theta^{\theta} \bar{p} f_{j} \bar{t} v \bar{p} u_{j \bar{t}} v \bar{p} \\
& \sum_{j=1}^{J} \sum_{v=-v}^{\bar{t}} u_{j \bar{t} v \bar{p}} \geq Q_{\bar{t} \bar{p}} \\
& 0 \leq u_{j \bar{t} v \bar{p}} \leq a_{j v} \bar{x}_{j v} \quad \begin{array}{l}
j=1,2, \ldots, \frac{J}{v}=-v, . ., \bar{t} \\
\end{array}
\end{aligned}
$$


Observe that (2-8) is a one constraint linear program with bounded variables. Hence, the optimal solution to this "knapsack" type problem can be obtained by simple ranking procedures without recourse to sophisticated mathematical programming algorithms. It should come as no surprise that the classical "knapsack" ranking method applied to $(2-8)$ is equivalent to what is commonly termed merit order dispatching in electricity economics.

The fact that $(2-8)$ is readily solved by simple merit order ranking procedures is what suggests the existence of a more elegant solution strategy. For a fixed set of capacity variables $\left\{\bar{x}_{j v}\right\}$ solve $(2-8)$ and $i$ ts dual. The dual solution generates certain prices which help guide the choice of a different set of capacity variables, say $\left\{\hat{x}_{j v}\right\}$, which, in turn, are used in (2-8). The process is continued until the capacity variables, $\left\{x_{j v}{ }^{*}\right\}$, are optimally chosen, and the subsequent solution of (2-8) leads to an associated set of optimal production variables, $\left\{u_{j t v p}^{*}\right\}$.

This second al ternative of decomposition would be of little practical value if the capacity expansion problem were always cast in the linear programming framework of $(2-6)$. Today, a problem with 1500 constraints is not considered that large or unwieldy, so why not solve it directly? However, more recent extensions of (2-6) include certain nonlinear constraints which make the solution of (2-6) intractable, al though (2-8) remains quite solvable. In these cases decomposition may be the only viable alternative. Certain of these extensions and nonlinearities are described later in Chapter 7 of this report. 
PART II --DECISION-MAKING AND UNCERTAINTY 
Chapter 3

\section{Uncertainty and the Behavior of the Firm}

\section{Overview}

Familiar conclușions from classical (deterministic) economics are phases such as "the competitive firm determines output so that price is equal to marginal cost" or the maximizing monopolist sets "marginal revenue equal to marginal cost." The subject of this chapter concerns the impact of uncertainty upon these behavioral conclusions. To help fix ideas consider the competitive firm whose output decision is determined by solving the following problem:

$$
\begin{aligned}
\max p q & -c \cdot x \\
q & =\phi(x) \\
q, x & \geq 0 .
\end{aligned}
$$

Here, $p$ is the price, $q$ the output, $x$ the vector of inputs, $c$ the input factor costs, and $\phi(x)$ is the production function. The KuhnTucker variable $\lambda$ would represent the marginal production cost. A straightforward application of the Kuhn-Tucker conditions shows that if $\left(q^{*} x^{*}\right)$ is an optimal solution to $(3-1)$ then

$$
\frac{d(p q)}{d q}=\lambda
$$

or

$$
p=\lambda \text {, }
$$

i.e., $q^{\star}$ is chosen so that price is equal to marginal cost. 
The main issue of this section is the assessment of what impact the explicit inclusion of uncertainty in (3-1) has upon behavioral conclusions such as (3-2). For example, suppose that $p$ is a random variable. Is it true that the uncertainty extension of (3-2) is

$$
E(p)=\lambda ?
$$

Surprisingly, this is not in general true.

Elements of uncertainty enter into (3-1) in at least three different ways. These are

(1) uncertainty about output price $p$,

(2) uncertainty about input factor prices $c$,

(3) uncertainty about the production technology embodied by the function $\phi$.

For the most part the economic literature has been concerned with (1), uncertainty about output price $p$. This is partly explained by the fact that (2) and (3) apparently are more difficult problems. For example, Gilbert and Stiglitz [15] stated the situation as follows:

If firms must choose inputs before their price is known (fuel, labor, etc.), and if the output price and lechinulugy are cerlain then it is not in general possible to say what effect this uncertainty has.

The scope of this chapter is limited to the effect of uncertainty about the output price $p$. The objective is to characterize how this uncertainty affects $q^{*}$, the optimal output, as well as $x^{*}$, the optimal inputs. However, the analys is will also be applicable to the imperfect competitor, i.e., the extension of (3-1) to the case 
in which price, $p$, is a function of $q$. The main references for this review are Sandmo [26], Leland [1,9], Holthausen [17] and Hartman [16]. In addition, the recent work of Gilbert and Stiglitz [15] should be emphasized. This report, entitled "Effects of Risk on Prices and Quantities of Energy Supplies" represents a comprehensive summary and analysis of the economic literature concerning uncertainty and the behavior of both firms and industries. The remainder of this chapter is divided into three sections. In the next section a brief review of utility functions and their connection with problem (3-1) is presented. Following this, some of the main theorems concerning the impact of output price uncertainty are developed. Finally, some brief comments concerning the impact of uncertainty on general equilibrium issues, as contrasted with individual firms, is presented.

\section{Utility Functions}

The $i$ dea that underlies the notion of a utility function is simply that the intrinsic value of wealth to an individual or firm may not be additive. In the usual case the notion of a utility function is illustrated by the graph in Figure 3-1. 
Utility

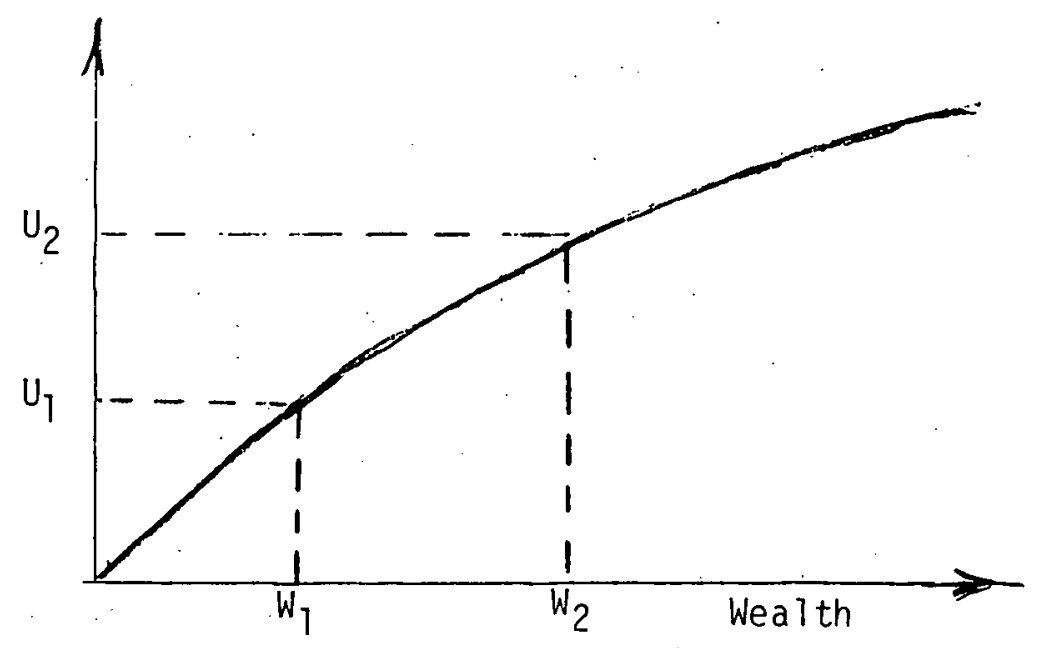

Figure $3-1$

An Illustrative Utility Function

The two values of wealth, $W_{1}$ and $U_{2}$, lead to utilities $U_{7}$ and $U_{2}$, respectively. The concave shape implies that increased wealth generates more utility, but at a decreasing rate.

It is commonly believed that the general shape of the utility function illustrated in Figure $3-1$ is representative of most individuals and firms. Individuals and firms with such utility functions are said to be "risk-averse." A more precise detinition is glven by Gilbert and Stiglitz [15]:

An individual is said to be risk-averse if he will not undertake a fair gamble, i.e., a risk with zero expected return. An individual is said to be risk neutral if he is just indifferent to accepting. such a risk, and an individual is a risk-preferrer if he prefers accepting such a risk. More formally, we let the individual's income from other sources be $Y$ and we assume for simplicity that $Y$ is a constant. Let $x$ be a gamble, i.e.., a risky prospect, with zero expected value, i.e., $E x=0$. Then if the utility function is denoted by $U$, we say that 
if $E U(Y+X)<U(Y)$ the individual is risk-averse

if $\operatorname{EU}(Y+x)=U(y)$ the individual is risk-neutral

if $E U(Y+X)>U(Y)$ the individual is a risk-preferrer

Subsequently, Gilbert and Stiglitz [15] show that these definitions are equivalent to the utility function being, respectively, concave, linear and convex.

If one believes that utility functions truly represent and explain the behavior of firms and individuals, then one must make important changes in the mathematical models set forth as describing rational decision-making. For example, instead of $(3-1)$ one should solve

$$
\begin{aligned}
\max U[p q-c \cdot x] \\
q=\phi(x) \\
q, x \geq 0,
\end{aligned}
$$

where $U(\cdot)$ represents the utility of (net) profit to the firm. Program (3-4) is well-defined as long as the utility function $U(\cdot)$ is well=defined and all the quantities are deterministic. If $p$ is a random variable, then the usual objective assumed in the economic literature is that the firm maximizes expected utility i.e., 


$$
\begin{gathered}
\max E\{U[p q-c \cdot x]\} \\
q=\phi(x) \\
q, x \geq 0 .
\end{gathered}
$$

As an example of (3-5) let $\pi$ represent net profit and suppose that

$$
U(\pi)=\sqrt{\pi}
$$

and that $p$ is a random variable which takes on the values of 5 and 15 with equal probability. Further, let $x$ be a scalar, assume $\phi(x)=\sqrt{x}$, and $c=1$, i.e., $(3-5)$ becomes

$$
\begin{aligned}
& \max E\left[\left(p q-q^{2}\right)^{1 / 2}\right] \\
& q \geq 0 .
\end{aligned}
$$

Problem $(3-6)$ is equivalent to

$$
\begin{aligned}
& \max \frac{1}{2}\left(5 q-q^{2}\right)^{1 / 2}+\frac{1}{2}\left(15 q-q^{2}\right)^{1 / 2} \\
& q \geq 0
\end{aligned}
$$

which yields an optimal solution of $q^{\star}=3.74$. In contrast, consider a problem related to (3-6) which is derived by simply replacing the random variable with $i$ ts expected value, i.e., $E(p)=10$. This problem is

$$
\begin{aligned}
& \max \left(10 q-q^{2}\right)^{1 / 2} \\
& q \geq 0
\end{aligned}
$$


which has the unique optimal solution of $q^{\star}=5$. Observe, then, that the explicit inclusion of uncertainty results in an optimal output $q^{*}=3.74$ which is strictly less than what one obtains from the socalled certainty counterpart, i.e., the problem in which the random variable is replaced by its expectation. This example is also illustrative of the general nature of the following section. The example just presented illustrates the classic result of Sandmo [26] in which it is shown that price uncertainty for risk-averse firms leads to a smaller output.

A final comment concerning this example is important. If the utility function is linear, then the deterministic counterpart to (3-5) results in the same optimal solution as $(3-5)$. This follows since

$$
E\{U[p q-c \cdot x]\}=E(p) q-c \cdot x .
$$

Hence, for risk-neutral firms and individuals the replacement of the random variable $p$ with its expected value leads to the correct solution.

Some Classic Results

One of the most often quoted papers concerned with uncertainty and the behavior of the firm is Sandmo's 1971 work [26]. In this paper Sandmo investigates the hehavior of the risk-averse, competitive firm for the case of output price uncertainty. Using Sandmo's notation, let profit, $\pi$, be defined as 


$$
\pi=p q-C(q)-B
$$

where price $p$ is a random variable with $E(p)=\mu, C(q)$ is the variable cost function and $B$ represents the fixed costs. The expected utility of profit is

$$
E\{U[p q-C(q)-B]\}
$$

where $U$ is assumed to be concave.

The application of the usual necessary conditions for an optimum to (3-7) yields

$$
\frac{d}{d q} E\{U[p q-C(q)-B]\}=0
$$

However, it appears to be standard practice in the economic literature to assume the validity of interchanging limit operations so that $(3-8)$ is written

$$
E\left\{\frac{d}{d q} U[p q-C(q)-B]\right\}=0 \text {. }
$$

An application of the chain rule yields

$$
E\left\{U^{\prime}(\pi)\left(p-C^{\prime}(q)\right)\right\}=0
$$

as a set of necessary conditions for an optimum. Rewritting (3-9) yields

$$
E\left\{U^{\prime}(\pi) p\right\}=E\left\{U^{\prime}(\pi) C^{\prime}(q)\right\}
$$


Then, subtracting $E\left\{U^{\prime}(\pi)_{\mu}\right\}$ from both sides results in

$$
E\left\{U^{\prime}(\pi)(p-\mu)\right\}=E\left\{U^{\prime}(\pi)\left(C^{\prime}(q)-\mu\right)\right\} .
$$

Next, observe that

$$
E(\pi)=\mu q-C(q)-B
$$

hence,

$$
\pi=E(n)+(p-n) q .
$$

Since $U(\cdot)$ is concave it follows that $U^{\prime}(\cdot)$ is non-increasing. Hence, if $p \geq \mu$ it follows from $(3-11)$ that

$$
U^{\prime}(n) \leq U^{\prime}(E\{n\}) .
$$

On the other hand, if $p \leq u$, then

$$
U^{\prime}(1) \cong U^{\prime}(E\{\Uparrow\})
$$

Hence, from (3-12) and $(3-13)$ it follows that

$$
U^{\prime}(\text { iI })(p-\mu) \leq U^{\prime}(E\{\pi\})(p-\mu)
$$

for all p. Taking expectations of both sides of (3-14) provides

$$
E\left\{U^{\prime}(\pi)(p-\mu)\right\} \leq U^{\prime}(E\{\pi\}) E\{p-\mu\} .
$$

But the right-hand side of $(3-15)$ is zero; since $E\{p-\mu\}=0$. Subsequently combining $(3-10)$ and $(3-15)$ then yields 


$$
E\left\{U^{\prime}(\pi)\left(C^{\prime}(q)-\mu\right)\right\} \leq 0
$$

Finally, since $U^{\prime}(\pi) \geq 0$ it follows that

$$
C^{r}(q) \leq \mu
$$

which implies that the optimal output is characterized by marginal cost being less than expected price. Equation (3-16) is the important insight provided by Sandmo [26].

Lel and provides an important extension of (3-16) to the case of a quantity setting, imperfect competitor. This is done through what Lel and terms "random demand curves," i.e., an implicit demand relationship

$$
f(p, q, u)=0
$$

in which $u$ is a random variable that is not known ex ante. It is assumed that this implicit function can be solved to yield

$$
p=p(q, u) \text {. }
$$

The quantity setting firm seeks to solve

$$
\begin{aligned}
& \max E\{U[p(q, u) q-C(q)-B]\} \\
& q \geq 0
\end{aligned}
$$

Observe that the competitive firm is the special case of (3-17) in which $p(q, u)=p(u)$. 
Leland shows, subject to some mild regularity conditions, that the optimal output of the quantity setting firm subject to uncertain demand is smaller than it would be in the certainty counterpart. The certainty counterpart is

$$
\begin{aligned}
& \max U[f(q) q-C(q)-B] \\
& q \geq 0
\end{aligned}
$$

where $f(q)=E\{p(q, u)\}$, i.e., $f(q)$ is an ordinary demand curve. The results of Sandmo and Leland deal with the impact of price uncertainty on the optimum output level $q^{*}$. A different issue is considered by Hol thausen [17] and Hartman [16]. If the production function is

$$
q=\phi(K, L) \text {, }
$$

where $K$ is capital and $L$ is labor, then what impact will price uncertainty have upon optimal choices of $K$ and $L$ ? In particular, does it follow that optimal choices $K^{*}$ and $L^{*}$ under uncertainty are less than equal to capital and labor choices in the certainty counterpart?. In part, the answers to these questions are provided by Hol thausen [17]. Holthausen shows that competitive firms and imperfectly competitive quantity setting firms facing uncertain demands choose least cost combinations of capital and labor. The details of this anailysis are shown next.

The production function $(3-18)$ is assumed to have the usual properties, i.e., positive marginal products with diminishing 
returns: However, it is assumed that the level of capital stock must be chosen before the random component of demand, $u$ of $p=p(q, u)$, is known. Hence, capital. stock is assumed to be an ex ante control while labor is an ex post control. These assumptions mean that one should think of labor, $L$, as a function of capita 1, K, and output, $q$ :

$$
L=\psi(q, K) .
$$

Hol thausen states,

This formulation emphasizes the assumption that labor is flexible and can be used to satisfy any level of demand. In fact, once the levels of $q$ and $K$ are determined, it is assumed that the firm's use of labor is determined by the labor requirements function. Hence, labor is not considered a decision variable. . .

To complete the specification of the model it is assumed that the firm purchases its inputs in completely competitive markets. In other words labor is priced as a constant $w$ per unit and capital is priced at a constant $c$ per unit. Further, $i$ is the opportunity cost of capital. Hence, the profit ii for the firm is

$$
\pi=p(q, u) q-w \psi(q, K)-i c k
$$

where $p(q, u)=p(u)$ for the perfect competitor. The objective of the firm is the maximization $E\{U(\pi)\}$ where $U$ is assumed to be concave. The first-order necessary conditions yield 


$$
E\left\{U^{\prime}(\pi)\left[p(q, u)+q \frac{\partial p(q, u)}{\partial q}-w \frac{\partial \psi(q, K)}{\partial q}\right]\right\}=0
$$

and

$$
E\left\{U^{\prime}(\pi)\left[-w^{\partial-\psi} \frac{(q, K)}{\partial K}-i c\right]\right\}=0 .
$$

Then, according to Hol thausen,

Since the firm sets both $q$ and $K$ ex ante, the amount of labor required, given by $L=\psi(q ; K)$, is known before $u$ is revealed. Thus $\psi(q, K)$ is not stochastic and $(3-20)$ can be written

$$
\left[-w-\frac{\partial \psi(q, K)}{\partial K}-i c\right] E\left\{U^{\prime}(\pi)\right\}=0,
$$

which means that

$$
\frac{-\partial \psi(q, K)}{\partial K}=\frac{i c}{w}
$$

But (3-21) is just the deterministic rule for cost minimization. The firm employs capital and labor in such amounts that the marginal rate of substitution between inputs equals their ratio of prices. Thus, the quantity-setting firm uses the least cost combination of capital and labor to produce the level of output it chooses. . . It should be noted that although the quantity setting. firm facing stochastic demand uses the deterministic rule for cost minimization, it does not necessarily use the same levels of capital and labor as the firm operating under uncertainty does.

- The final sentence in the preceding quote from Hol thausen is further clarified by Hartman [16], 


\begin{abstract}
- . the firm will choose its inputs to minimize the cost of producing whatever level of output is chosen. This result, combined with the Sandmo result that the presence of uncertainty reduces output, implies that the effects of uncertainty on factor demands depend upon what effect the decreased output due to uncertainty has on the cost minimizing levels of inputs. Except for the rare case of inferior factors, the presence of uncertainty reduces factor demands.
\end{abstract}

Uncertainty and General Equilibrium

According to Gilbert and Stiglitz [15] the current understanding of general equilibrium economics subject to uncertainty is not well understood. They put it as follows:

At the present time the general equilibrium theory under uncertainty is in a rather unsatisfactory state. It is not even clear what are the empirical phenomena which the model should explain. For instance, al though many economists would argue that'it is obvious that firms face downward sloping demand curves for their shares and that their market value depends on their debt equity ratio, others might well disagree. Even if they agree, they may say that the basic theory is correct but there are other distortions (e.g., taxes) which explain what is going on; e.g., their theory would correctly predict what would be true if there were no taxes.

However, there are some previous approaches to modelling general equilibrium under uncertainty. One of these is Arrow [2] which is reviewed by Gilbert and Stiglitz [15]. The following passages highlight the review of Arrow from the point of view of Gilbert and Stiglitz.

The Arrow approach is analogous to a method of extending ordinary static analysis to a dynamic framework. This is done by "dating" all commodities and assuming the existence of a complete set of markets, 
i.e., future markets for each commodity exist at all points in time. Instead of a single commodity $x$, a sequence $\left(x_{1}, x_{2}, \ldots\right.$, $\left.x_{t}, \ldots ..\right)$ is used and the intertemporal complication is avoided, al though the scope of the static analysis is greatly enlarged. Arrow then noted that the same "trick" could be used by associating a given commodity with different states of nature. Gilbert and Stiglitz further explain as follows:

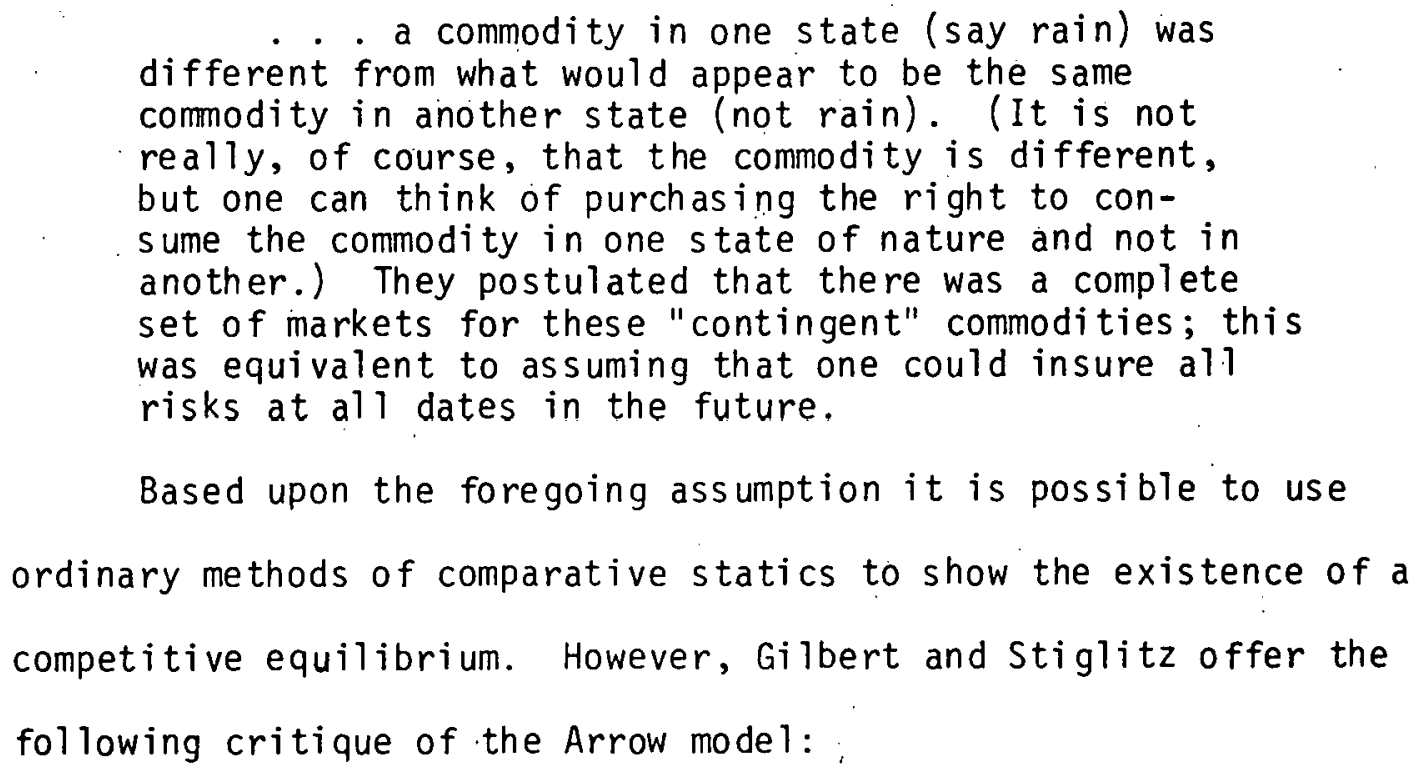

Based upon the foregoing assumption it is possible to use ordinary methods of comparative statics to show the existence of a competitive equilibrium. However, Gilbert and Stiglitz offer the following critique of the Arrow model:

The full set of markets which are required for the theorem obviously do not exist and there are strong a priori reasons why une should nut expect theiim to. . . . if the theory were correct; a manager would only need to calculate the "Arrow-Debreu prices". (the prices corresponding to output of each commodity in each state of nature at each date) and evaluate each project using those prices to determine what investment decisions should be made. There would never be any disagreements, take-over bids would never occur, etc.

It is also of interest to note what directions for future work are advocated by Gilbert and Stiglitz. They say 
. . . the general equilibrium aspects which appear to be important are not those associated with largescale programming models, nor even detailed econometric models, but rather with a more detailed specification of the behavioral response of the firms and consumers in the economy to uncertainty, and their interactions through capital markets and commodity markets. 
PART II I--CAPACITY EXPANSION UNDER UNCERTAINTY 


\section{Chapter 4}

\section{Sequential Uncertainty and Decision Analysis}

This chapter summarizes an approach to incorporating uncertainty into supply planning models of electric utilities. The approach was first advocated by Cazalet, Judd et al. [8] and later extended and applied by Cazalet, $\mathrm{Cl}$ ark et al. [9] and Sanghvi and Limaye [27]. This approach has been termed the decision analysis method because of its formal relationship with classical decision theory.

The methodological approach is based upon the idea of "rolling production schedules" as described, for example, by Wagner [35]. However, the future demands are known only stochastically so that one may plan capacity expansion based upon a certain demand forecast which is never realized. Sanghvi and Limaye [27] characterize the methodology as follows:

Specifically, it determines the economic impact of planning for one load growth rate when another rate is realized.

The conceptual nature of the method can be illustrated by a simple example. Suppose that the demand for electricity over the next four periods is represented by the 4-tuple $\left(D_{1}, D_{2}, D_{3}, D_{4}\right)$ where each $D_{t}$ is a random variable. Moreover, assume that the random variables are not mutually independent, i.e., the distribution of $D_{2}$ depends upon $D_{1}, D_{3}$ upon $D_{2}$, etc. At time $t=0$ the expected demands are $\left(E\left(D_{1}\right), E\left(D_{2}\right), E\left(D_{3}\right), E\left(D_{4}\right)\right)$, e.g., the expected demands may be $(4,6,9,11)$. Based upon this expectation, certain capacity expansion plans are initiated. Such plans may call for the immediate acquisition 
of some facilities with a short acquisition lead time, while the plans could also initiate siting and licensing procedures for longer term acquisitions. A plan may indicate a firm acquisition of $x_{1}$ units for period 1, and the potential for acquiring $x_{2}$ additional units of capacity in period 2. However, some or all of this $x_{2}$ capacity may be postponed pending the actual demand which occurs in period 1 .

If the actual demand in period 1 is 3 units, then a temporary condition of overcapacity most likely occurs. Recall that the expected demand for period 1 (at $t=0$ ) was 4 units. The occurrence of a smaller demand in period 1 affects the nature of demand in all future periods. The demands in periods $2,3,4$ and 5 are random variables of the form $\left(D_{t} \mid D_{1}=3\right)$. Given that $D_{1}=3$, a new (conditional) distribution is specified in all remaining periods. Revised capacity planning decisions would be based upon the conditional expected values of demand:

$$
\left[E\left(D_{2} \mid D_{1}=3\right),\left(E\left(D_{3} \mid D_{1}=3\right) \cdot . \cdot\right]\right.
$$

This revised forecast of expected demands would lead, in general, to changes in earlier plans for schedule additions. Such changes might be in the form of delays, postponements, or even cancellations. The revised forecasts also affect the nature of current expansion plans. Given that $D_{1}=3$, one may specify a (conditional) expected demand for the next four periods of, 5 dy, $(5,7,10,13)$. Observe that expected demand in period 2 is now revised downward from 6 to 5 . 
The dynamics of the conditional demand forecasts are illustrated in Figure 4-1. Observe that the actual demand in period $t=1$ will be either 6,5 or 3 with probabilities (shown in the branches in Figure 4-1) of .3, .5 and .2, respectively. Hence, the expected demand in period 1 is

$$
(.3) 6+(.5) 5+(.2) 3=3.9
$$

Furthermore, the expected demand in period 2 is

$$
(.3)(.4) 9+(.3)(.5) 7+\ldots+(.2)(.3) 2=5.83
$$

However, the conditional expected demand for period 2, given $D_{1}=6$, is

$$
(.4) 9+(.5) 7+(.1) 5=7.6
$$

In other words, at $t=0$ the expected demand for the next two periods is $(3.9,5.83)$. But, if the actual demand in period 1 is 6 , then the expectation for period 2 is revised upwards from 5.83 to 7.6 .

One of the main thrusts of the decision analysis approach is to determine the manner in which capacity $\mathrm{plans}$ are continually revised as the actual demand unfolds in a sequential manner. (The number of different ways the demand might unfold corresponds to the number of branches in the decision tree. For the example in Figure 4-7 the number of alternative demand sequences is nine.) Capacity expansion is slowed or accelerated in accordance with how well current capacity matches current demand. In this manner the actual capacity at each node in the 


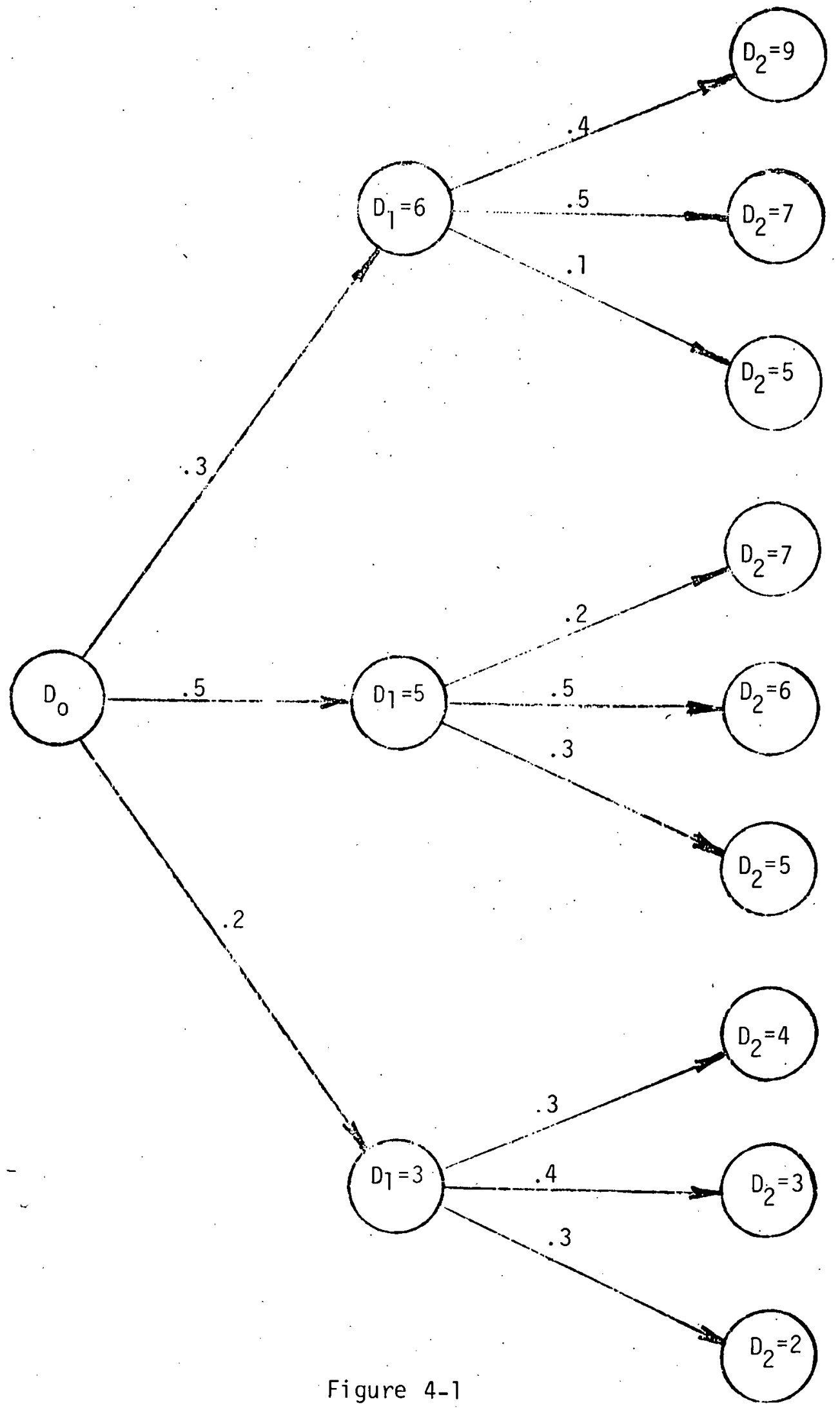

Decision Analysis Framework 
decision tree will be either "over or under" the actual demand. Assuming some fixed shortage cost per kwh, one can then compute an average cost per Kwh at each node. In particular, one can compute an expected average cost per $\mathrm{Kwh}$ for each period $t$. One of the unique features of this planning methodology is that the expected average cost in each period $t$ explicitly includes the costs of forecast errors, i.e., cases for which capacity expansion plans are not consistent with actual demands. It is in this sense that Cazalet et al. [9] argue that the decision analysis approach takes a major step forward in modelling the actual behavior of electric utilities:

The methodology of this study takes a major step in the direction of developing a flexible planning process that can reflect the uncertainty that is present. By starting with the view that future demand is uncertain, we can provide a formal, quantitative method of stating the level of uncertainty. Having recognized future demand as uncertain, we can then provide a decision structure that represents the degree of available flexibility in planning, construction and operating a variety of new plants with different costs and planning lead times. The result is a planning methodology that provides a clear, logical basis for capacity expansion decisions that does not require a single forecast of future demand.

For a further resolution and understanding of the decision analysis approach it is useful to contrast the static and dynamic versions of the process. In the static version there is only a single period, and hence no recourse is available to the utility managers at period 1 (since there is no period 2). The static version is one in which the decision tree has only one node with branches emanating. One such tree is $i 11$ ustrated in Figure 4-2. 


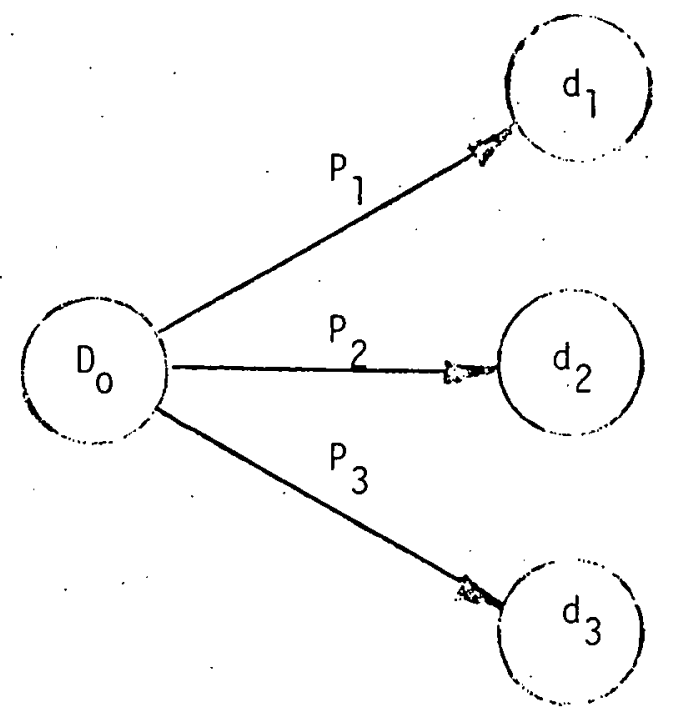

Figure 4-2

Decision Analysis in a Static Framework

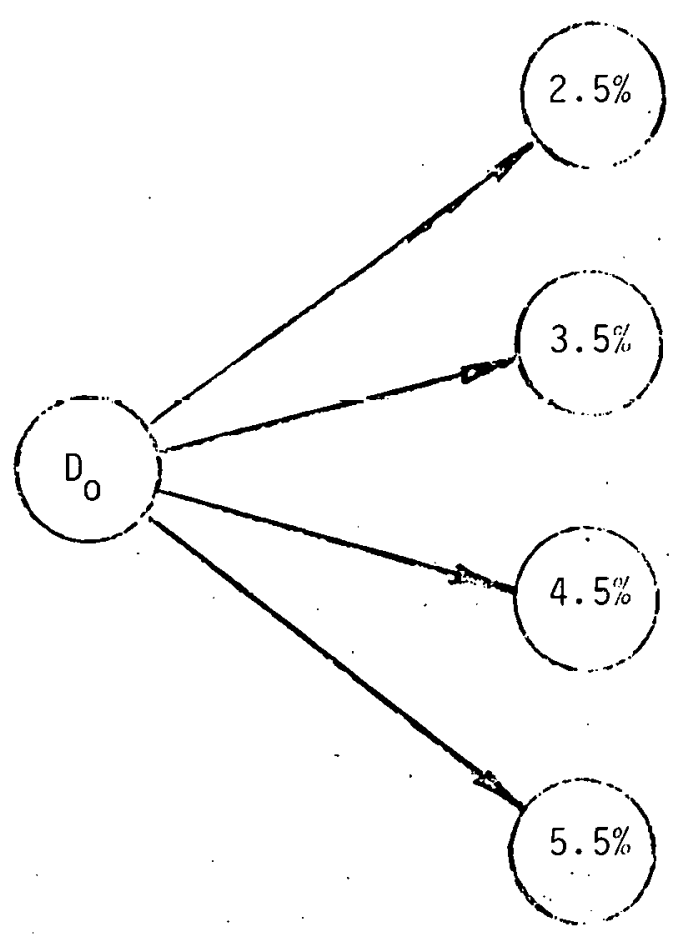

Figure 4-3

Example of Sanghvi and Limaye 
The earliest version of the work by Cazalet et al. [8] utilized the static one period model. Since the client and first application of this model was the State of California, this model has been termed the "California" model. A subsequent workshop concerning the validity of the California model was sponsored by the Electric Power Research Institute in July 1977. According to Cazalet et a1. [9] an appraisal of the California model stated:

The workshop identified two main areas of weakness in the California model. The first was the over simplification of the production costing, financial and system reliability calculations. The second weakness was the model's neglect of the inherent flexibility in the utility $\mathrm{planning}$ process to respond to changing expectations of demand growth by changing expansion $\mathrm{plans}$.

The resolution of the second problem resulted in the development of a dynamic framework in which feedback on the state of the system (in this case, demand) permits adjustment of the capacity expansion plan. Clearly, this is a more sophisticated approach than the static model. However, it tends to mask the more fundamental nature of the decision analysis methodology. This fundamental methodology is conveniently illustrated with an example taken from Sanghvi and Limaye [27]. The example corresponds to Figure $4-3$ in which four different load growth rates are possible. These load growth al ternatives correspond to the $2.5 \%, 3.5 \%, 4.5 \%$, and $5.5 \%$ (per annum) rates which are illustrated in Figure 4.3.

In the example by Sanghvi and Limaye the alternative supply responses are in one-to-one correspondence with the alternative demand 
forecasts (although, clearly such an assumption is not required). This means the four different suppiy responses are to expand capacity at an annual rate of $2.5 \%, 3.5 \%, 4.5 \%$, or $5.5 \%$. Hence, one might expand capacity at a $2.5 \%$ rate only to observe subsequently that demand has grown at $5.5 \%$. In this case shortages undoubtedly will occur because of the shortfall in capacity. On the other hand, one might expand capacity at $4.5 \%$ and observe a demand growth of $3.5 \%$. Higher than acceptable reserve margins clearly will result from this latter case.

The framework of the classical decision analys is approach for the Sanghvi and Limaye example is shown in Table 4-1. In this table the overall cost per Kwh for every possible pair of expansion alternative and demand occurrences is depicted. (The cost per Kwh is determined by other procedures which take into account capital costs, current expenses, shortage costs, etc.)

Table 4-1

Static Decision Analys is Illustration

Load Growth Outcome

\begin{tabular}{|c|c|c|c|c|c|}
\hline & & $2.5 \%$ & $3.5 \%$ & $4.5 \%$ & $5.5 \%$ \\
\hline & $2.5 \%$ & $29.5^{\star}$ & 54.5 & 123.5 & 226.2 \\
\hline Capacity & $3.5 \%$ & 32.9 & 32.0 & 56.3 & 140.9 \\
\hline Expansion & $4.5 \%$ & 40.1 & 37.1 & 37.2 & 71.1 \\
\hline & $5.5 \%$ & 46.5 & 42.3 & 39.5 & 39.6 \\
\hline
\end{tabular}


The entry 46.5 represents the average cost per Kwh if capacity is expanded at $5.5 \%$ while demand grows at only $2.5 \%$. Conversely, if capacity is expanded at $2.5 \%$ and demand grows at $5.5 \%$, then the average cost per Kwh is 226.2, a result which influences Sanghvi and Limaye to infer that "overbuilding" is better than "underbuilding".

Ultimately, the question is which capacity expansion rate should one choose. In particular, then, how does one use the data in Table 4-1 to help make a decision? The answer in part depends on what criterion is chosen. A so-called "maximin" solution is to expand capacity at $5.5 \%$ because in this alternative the maximum cost per Kwh (46.5 mills/Kwh) is smaller than the maximum cost per Kwh that could occur under any other alternative. A different criterion is the expected value method, a method that requires an explicit assumption concerning the probability of each alternative demand forecast. Suppose, for example, that the probability of load growths for $2.5 \%, 3.5 \%, 4.5 \%$, and $5.5 \%$, are $.05, .20, .50$ and .25 , respectively. The expected cost associated with the $2.5 \%$ capacity expansion program is

$$
(.05) 29.5+(.20) 54.5+(.50) 123.5+(.25) 226.2=130.7
$$

Similarly, the expected costs for the $3.5 \%, 4.5 \%$ and $5.5 \%$ capacity expansion programs are $71.4,45.8$ and 40.4 , respectively.

Based upon the expected cost per Kwh the optimal choice is to expand capacity at a $5.5 \%$ rate. However, it is well known that expected value decision-making may not be consistent with the risk-averse 
behavior that characterizes many individuals and firms. Sanghvi and Limaye stop short of advocating the use of Table 4-1 as a final arbiter. They conclude:

Without meaning to "pass the búck," in the final analysis, the decision to accept one expansion rate over the other, rests with the regulatory body. with the mandate to do so. Our decision analysis purposely falls short of recommending this final step, since the capacity expansion rate decision must also incorporate other socio-political considerations. However, our analys is provides an objective assessment of the econonic and environmental impacts of each decision al ternative. 
Chapter 5

\section{Modelling Uncertainty in System Dynamics}

\section{Overview}

System dynamics is an approach to modelling the behavior of complicated socio-economic systems. The term system dynamics was first used by Forrester [14]. In essence, system dynamics is a type of simulation in which a set of rules relating the behavior of individual elements of the system are somehow determined and then the system is "simulated" to observe the resulting behavior of the system. In simplest terms one might have a system with ten components, say $x_{1}, x_{2}, \ldots x_{10}$. The components may be related in forms such as

$$
x_{3}(t)=f\left[x_{1}(t), x_{3}(t-1), x_{7}(t), e_{j}(t)\right]
$$

and

$$
x_{6}(t)=g\left[x_{6}(t-1), x_{6}(t-2), \ldots . .\right]
$$

where $x_{i}(t)$ represents the state of $i^{\text {th }}$ component at time $t$ and $e_{j}(t)$ is the value of the $j^{\text {th }}$ exogenous variable at time $t$.

These two relationships illustrate part of the underlying philosophy of system dynamics. First, although one may be interested primarily in $x_{7}(T)$ (where $T$ is some particular time horizon) às a function of some trajectory of assumed exogenous values $\left.\mathrm{ie}_{4}(1), \mathrm{e}_{4}(2), \ldots, \mathrm{e}_{4}(T)\right]$, it may be unclear or unknown how $x_{7}(T)$ relates to this exogenous set of values. However, it may be understood how $x_{7}(T)$ relates to other variables and how these other variables relate to $\left[e_{4}(1), e_{4}(2), \ldots ., e_{4}(T)\right]$. If this is the case, the value of $x_{7}(T)$, as a function of the exogenous variables, can 
be realized by explicitly considering the set of intermediate components that relate to and, in part, determine $x_{7}(T)$. Second, system dynamics always includes the capability of a feedback loop in the characterization of the forward dynamics of the system, i.e., the decisions and the state of the system at time $t$ influences the state of the system in time $t+1$.

Although both of these properties of system dynamics are important, they are by no means unique to system dynamics. In fact, system dynamics itself is largely an outgrowth of the study and application of systems of differential equations to economic and business systems.

A system of (linear, ordinary) differential equations with constant coefficients is of the form

$$
\dot{x}=A x+B u+f(t)
$$

where $\dot{x}, x$ are $n$ dimensional, $A$ is $m x n, B$ is $m \times r, u$ (the control) is $r$ dimensional, and $f(t)$ is the forcing function. A closed form solution to this system would be of the form

$$
x(t)=g[u(t), t]
$$

In some cases it is possible to solve $(5-1)$ and obtained closed form solutions such as (5-2). However, it is more common, especially for more complicated nonlinear systems, to approximate $(5-1)$ by numerical integration procedures. Essentially, this is the same procedure one follows in system dynamics. One first models the "dynamics" of the system by constructing some mathematical representation where (5-1) is one such classical representation in continuous time. 
(However, in system dynamics one usually employs discrete time approximations and uses difference equations.) In this approach, observe that:

(a) $f(t)$, the forcing function, is to $(5-1)$ what the exogenous variables are to system dynamics,

(b) the sets of variables $x$ and $u$ are to (5-1) what "stock levels" and "decisions" are to system dynamics,

(c) the matrices $A$ and $B$ for (5-1) are what the "component relationships" are for system dynamics.

One other point should be made in this overview of system dynamics. Drawing the analogy of system dynamics with the differential equation systems such as (5-1) underscores the fact that probability and uncertainty are not intrinsic elements of system dynamics. This is important since oftentimes the term simulation is used to describe the implementation of system dynamics and the term simulation conjures up the notion of Monte Carlo methods. What is usually done in system dynamics is a "deterministic" simulation which is simply one "realization" of the system performance. This is an important point since the remainder of this section describes a methodological approach for incorporating uncertainty into a particular system dynamics model, namely the ELECTRIC 3 model [13].

The ELECTRIC 3 model is a system dyramics approach to modelling the electric utility system of the U.S. According to Stover, Hayward and Becker [31]: 
It is a system dynamics model constructed to "understand the underlying causes of the problems in the electric utility industry" and, hopefully, "to assist in the formation of policy." National in scope, it is designed to show how the U.S. utility industry will respond to changing energy conditions during the transition period between conventional power sources (e.g., domestic oil, coal) and what Ford foresees as the "ultimate" (nondepletable) sources of power--solar, fusion, and geothermal. . . Both the demand growth rate for electricity and the respective prices of the competing fuels are entered exogenously. The model calculates the industry's response to those external conditions, assuming certain utility planning procedures. It is not assumed that utilities are always successful in carrying out their plans.

The next section describes how Stover, Hayward and Becker [31] modified the ELECTRIC 3 system dynamics model to explicitly account for uncertainty. In essence, this next section is a review of [31].

Incorporating Uncertainty into ELECTRIC 3 .

Stover, Hayward and Becker [31] argue that most models are based on the past:

Information about past relationships is used to define the relationships in the model, which are then used to simulate the future. Any model that is based entirely on the past will be useful only for exploring the very nearterm future.

They continue by emphasizing the fact that with system dynamics one

can include a good deal of information about the future:

This information may be in several forms. Nonlinear. relationships included in the system dynamics models through table functions often depend on historical data for part of the range and on the modeler's perception of the future shape of the relationship for another part of the range. Relationships among variables that are not apparent today may be included in the model structure because of the assumed importance or these relationships in the future. However, an important class of information about the future--future events--is not usually considered. 
The notion of "future events" is the cornerstone of the approach to incorporating uncertainty into ELECTRIC 3. Future events are things that may happen in the future and things which would have a significant influence upon the evolution of the electric utility industry. Some examples taken from [31] are as follows:

(1) Peak-load pricing is adopted by at least 50 percent of all utilities.

(2) Inadequate rate of return prevents utilities from attracting necessary capital for at least three years in a row.

(3) Legislation is passed imposing a permanent moratorium on the construction of new nuclear plants.

(4) OPEC dissolves, lowering the price of foreign petroleum by 25 percent in real terms.

(5) Congressional legislation establishes strict coal stripmining standards.

Future events such as these are assumed to occur according to some a priori determined probability, which means that in a given simulation, future event (3) may or may not occur. The same is true for the other thirteen future events explicitly formulated in [31] to impact upon ELECTRIC 3. Furthermore, future event (3) might occur in 1984 in one run and in 1992 in another run. Hence, in a given simulation not only is the occurrence of a given future event subject to chance, but so is its timing.

The specification of the probability of occurrence of future events in ELECTRIC 3 is somewhat complicated in that the events are assumed to be mutually dependent. An example from [31 ] illustrates this point. Suppose that the initial probabilities for the following events are 
(.50) a) A strict strip-mining bill is passed by Congress.

(.25) b) A new oil embargo occurs.

(.10) c) A moratorium is imposed on new nuclear plants.

(.70) d) Peak-load pricing is implemented for all customers.

Then, a set of conditional probabilities are specified as shown in Figure 5-1.

The probability of this event becomes:

\begin{tabular}{|c|c|c|c|c|c|}
\hline \multirow{2}{*}{\multicolumn{2}{|c|}{ (a) }} & (a) & (b) & (c) & (d) \\
\hline & & $x$ & .25 & .10 & .70 \\
\hline \multirow{3}{*}{$\begin{array}{l}\text { If this } \\
\text { event } \\
\text { occurs: }\end{array}$} & (b) & .60 & $x$ & .05 & .80 \\
\hline & (c) & .70 & .30 & $x$ & .90 \\
\hline & (d) & .45 & .20 & .10 & $x$ \\
\hline
\end{tabular}

Figure $5-1$

Conditional Probabilities for Future Events

Observe that the occurrence of event (a) does not alter the probability of occurrence of events (b), (c) and (d), but in all other cases the relative probabilities are modified. For example, if $(c)$ occurs, then more coal plants, presumably, would be necessary. This increases the likelihood of more careful scrutiny of coal mining practices. The result is an increase in the likelihood of future event (a) from .50 to .70 . 
In ELECTRIC 3 the occurrence of future events also affects the model itself (termed event-model interactions). For example, suppose that coal prices are exogenously specified by a nominal function of time as follows:

$\begin{array}{ll}1980 & \$ 30 / \text { ton } \\ 1981 & \$ 32 / \text { ton } \\ 1982 & \$ 34 / \text { ton } \\ 1983 & \$ 36 / \text { ton } \\ 1984 & \$ 38 / \text { ton } \\ 1985 & \$ 40 / \text { ton }\end{array}$

But, if a strict strip-mining bill is passed, the price of coal increases 30 percent. Hence, if the mining bill (which is a future event) occurs in 1983, then coal prices over the 6-year horizon become:

$\begin{array}{ll}1980 & \$ 30 / \text { ton } \\ 1981 & \$ 32 / \text { ton } \\ 1982 & \$ 34 / \text { ton } \\ 1983 & \$ 46.80 / \text { ton } \\ 1984 & \$ 49.40 / \text { ton } \\ 1985 & \$ 52 / \text { ton }\end{array}$

Other impacts of future events on the model include such modifications as: --changing load factors (due to occurrence of peak-load pricing), --regulatory lag reduced to two months (due to occurrence of inadequate rate of return),

--price of foreign oil decreased by 25 percent (due to OPEC dissolving). 
Hence, the occurrence of future events, in addition to their direct influence, affects the structure of the model as well as the probability of occurrence of other future events.

Uncertainty is incorporated into ELECTRIC 3 in still another way. Several of the exogenous inputs (the most important being the annual growth rate of electricity demand) are also subject to stochastic perturbations. However, in this case the implementation is straightforward. One chooses some growth rate (from a distribution of growth rates) at the beginning of the simulation and uses this rate throughout the simulation. For example, if growth rates of 1, 2, 3 and 4 percent per year are equally likely, then for a particular simulation there is a 25 percent probability that the growth rate will be 4 percent per year. Correspondingly, about 25 percent of all simulations will have a 4 percent annual growth rate in electricity demand.

The actual mechanics of performing what is termed PSD (probabilistic simulation dynamics) is summarized in [31] as follows:

Once events and uncertainty distributions for important exogenous variables have been added to the model, a set of Monte Carlo runs can be performed. This involves a number of separate runs of the model in which random numbers are used to determine certain model values. Two types of random selection are involved. First is the one-time selection of random numbers to select values for exogenous inputs from the range of uncertainty for each variable. This selection is done at the beginning of the run and sets the value of the variable for the rest of the run.

The second type of random selection is a continuing selection to determine occurrence or nonoccurrence of events. In this process new random numbers are selected for each event at each solution interval of the run. In this first type of random selection, the one-time selection of a random number sets the value of exogenous inputs. In the second type the continuous 
selection of random numbers determines not only whether or not each event occurs but, if it occurs, also the timing of that occurrence. Thus the variation in model output from run to run is caused by three types of uncertainty:

- What values the exogenous inputs will have.

- Which events occur and which do not.

- When, during the course of the run, the occurring events will actually occur.

It is impossible to determine beforehand exactly how many runs will have to be made in order to develop a stable distribution for the model output variables. In most cases, the application.. . involved forty runs of the model in each Monte. Carlo set. A comparison of the first twenty runs with the last twenty runs generally showed little difference, indicating that forty runs were sufficient to generate a stable distribution. In general, one would expect that the number of runs required would increase as the uncertainty in exogenous variables and impact of events increases, and would also increase as the number of events and exogenous variables treated increases. The forty runs required for ELECTRIC 3 is probably representative of most of the applications to large simulation models that would be encountered.

Summary

The study by Stover, Hayward and Becker [31] is not meant to produce substantive results. It is a methodological study characterized by:

- . this study is to develop and demonstrate a a practical level the methodology of incorporating probabilistic considerations in energy supply models.

However, methodological studies inevitably resort to some sample runs and illustrative applications, and ELECTRIC 3 is no exception.

The illustrative examples discussed in [31] feature one interesting result, which will now be described. The ELECTRIC 3 model was exercised in two different modes: 
(a) Without future events

(b) With future events

It was suggested that one might reasonably expect outputs such as total installed capacity to appear as illustrated in Figure 5-2:

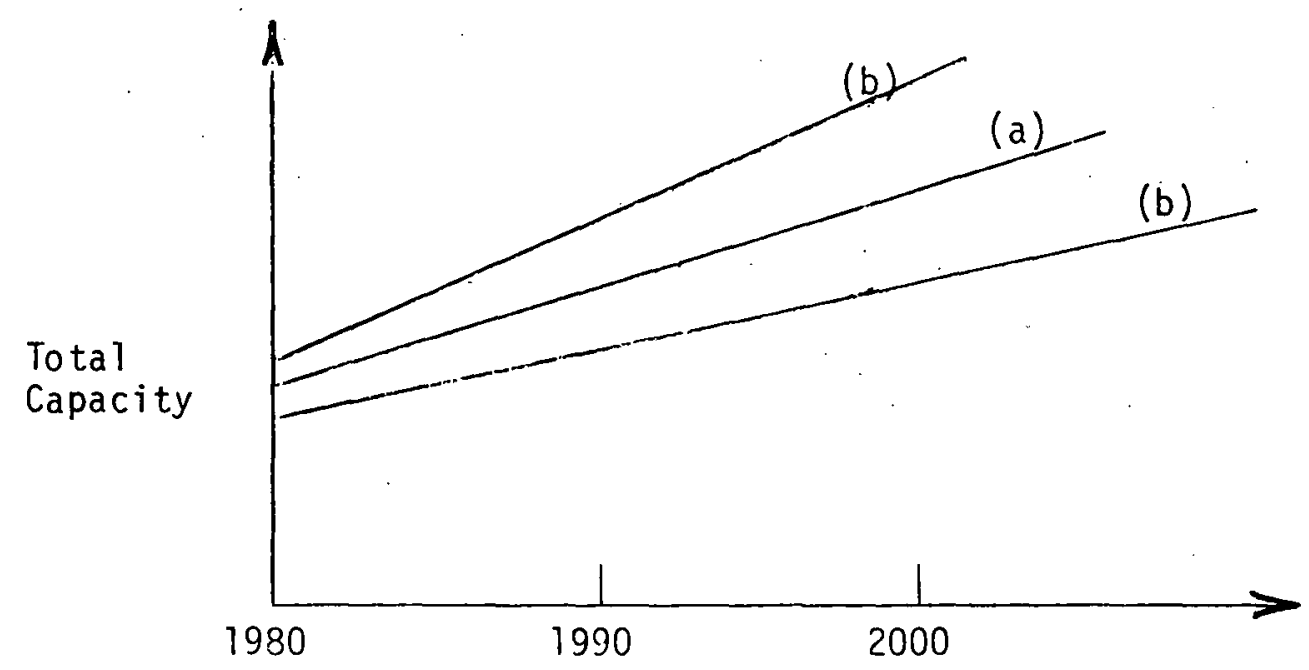

Figure 5-2

Projection of Capacity by ELECTRIC 3

In Figure 5-2 the upper and lower (b) lines correspond to the range of values for total capacity that are repeatedly generated by sampling from the future events. The baseline (a) represents the output of ELECTRIC 3 without the generation of future events. However, the baseline (a) for a number of important outputs is not contained within the range spanned by the (b) upper and lower bounds. Stover, Hayward and Becker [31] state:

It is interesting to note that in some cases the deterministic projections lie completely outside the interquartile range of the probabilistic run, indicating that events do make an important difference to the model behavior. 
However, one is cautioned that the generation, description probabilistic accounting of future events is highly subjective. The sponsors (EPRI) of the ELECTRIC 3 uncertainty extensions include the following passage in [31]:

Several cautions to the use of the model should be noted. Most importantly, future events in the model impact other variables by changing the input probabilities of those variables. As in all simulation models, these cause and effect relationships are not treated as structural functions derived from statistical analysis. They are based upon ad hoc estimates of the subject probabilities. Therefore, model results depend not only upon the chosen set of input probabilities of occurrence of future events, but also upon untested relationships between events and variables. 


\section{Chapter 6}

\section{Level of Reliability and}

\section{Capacity Choices}

This section discusses a rationale for balancing the need for increased reliability of the bulk power system against the concomitant cost of providing the additional generation capacity. The primary reference.for this section is Telson [34]. The essence of the tradeoff is illustrated in Figure 6-1.

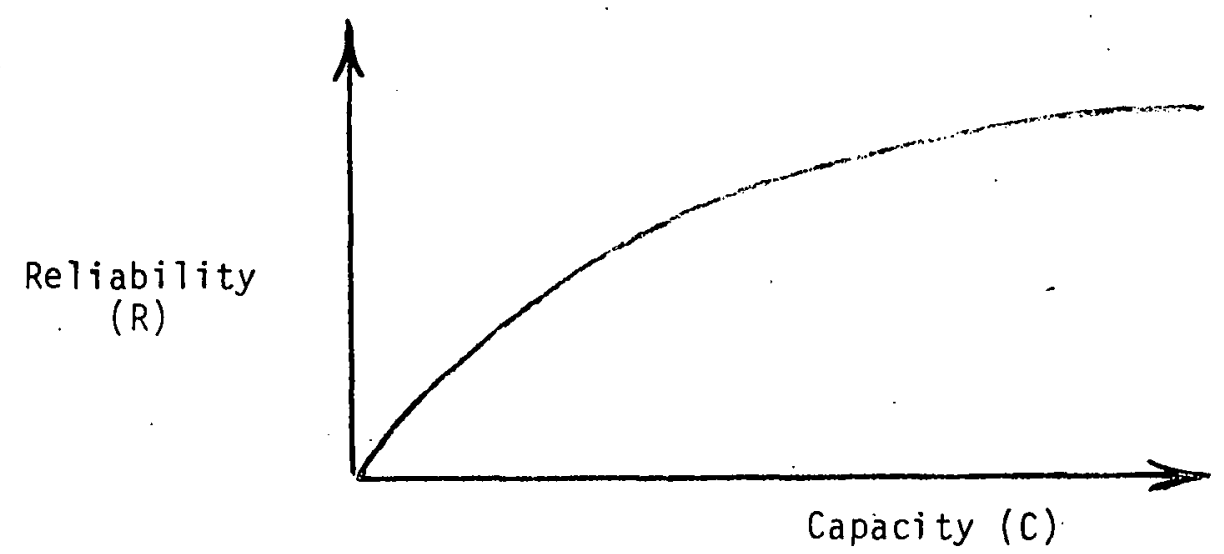

Figure 6-1

Reliability vs Capacity

Whatever measure of reliability is chosen, it is clear that increased generation capacity leads to increased reliability. The issue is what level of capacity represents the best compromise between higher reliability and the increased cost due to larger capacity requirements. One widely used measure of reliability of a bulk power system is the Loss of Load Probability (LOLP). Actually, the name is a misnomer for LOLP is neither a measure of load loss nor is it a probability. What 
LOLP represents is the expected number of days/year for which demand exceeds supply, e.g., a typical design value for LOLP is "1 day in 10 years." This means that if one observed a particular system for 10 years, then the expected total number of hours in which available generation capacity was insufficient to satisfy the load would be 24 hours. Such insufficiencies would be due to a combination of higher than expected demand and the occurrence of so-called "forcedoutages" of one or more generators. A more complete description of LOLP and its derivation is given in [30].

The problem addressed by Telson [34] is how to choose a point. $\left(C^{\star}, R^{\star}\right)$ from the curve in Figure $6-1$ (where the reliability measure is LOLP). The approach is to balance the cost of increased capacity with the value received by increasing the reliability.

Telson advocated a particular strategy. To illustrate, consider a system with $n$ generating units and a given load-duration curve. It is then straightforward to construct a curve such as Figure 6-1 that relates LOLP with capacity, e.g., the size and mix of the existing $n$ units gives rise to the associated LOLP. This represents one point on the curve. The question asked by Telson is, "How much additional energy will be generated by an incremental ( $n+j^{s t}$ ) plant with one megawatt of capacity?" The nature of this question is graphically illustrated in Figure 6-2, a figure that displays a typical load-duration curve . 


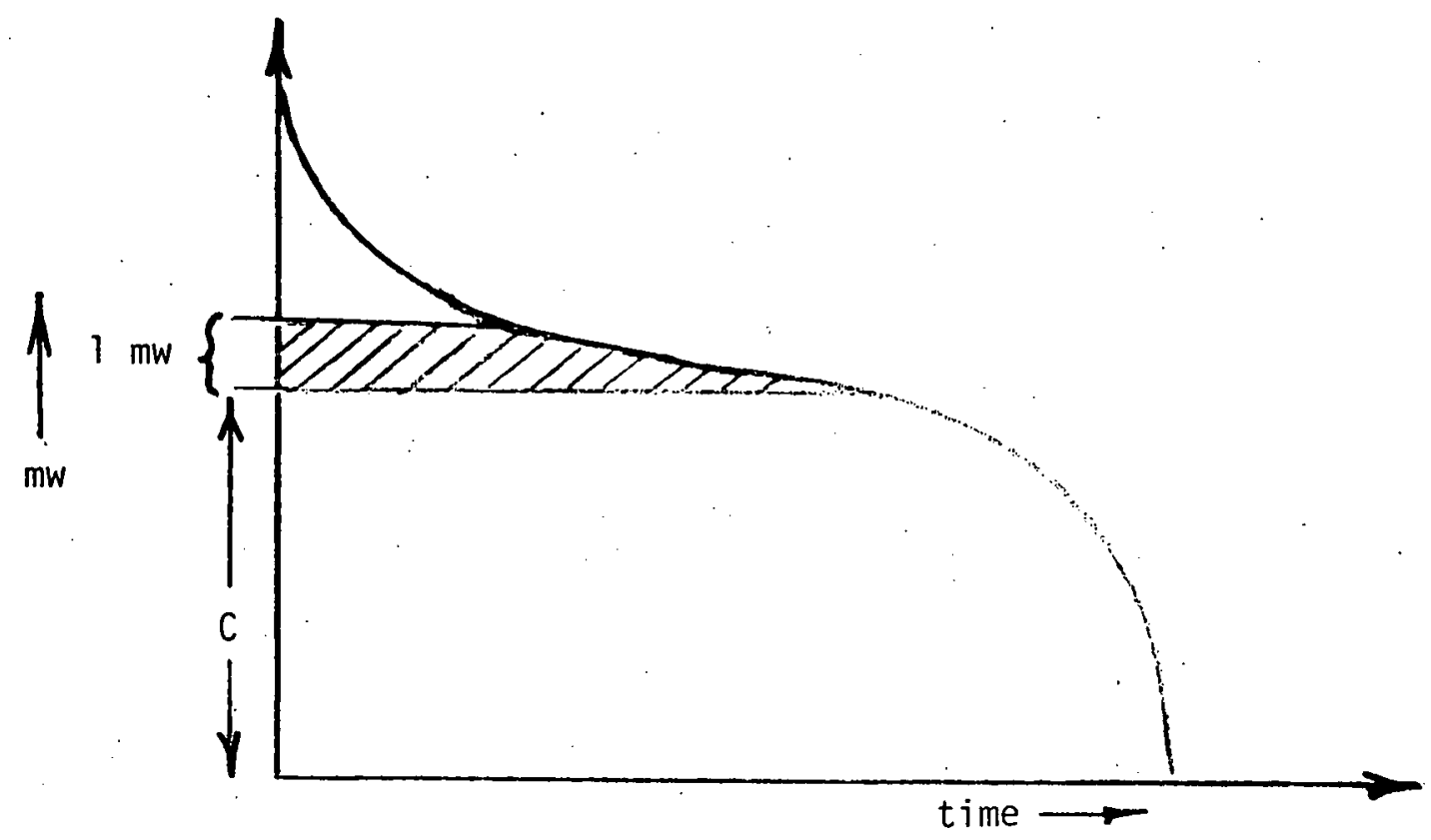

Figure 6-2

Typical Load-Duration Curve

The shaded area in Figure 6-2 represents the energy generated by a $1 \mathrm{mw}$ unit given that a total of $C$ megawatts have been previously dispatched. (Clearly, if $\hat{C}$ megawatts, $\hat{C}<C$, are dispatched, then the energy generated by the incremental 1 megawatt plant would be 1 arger.) However, is it not. true that $C$ simply should be equated to the total capacity of the existing $n$ units? The answer is "no" since the capacity of the existing $n$ units is not a fixed, deterministic value. The total available capacity associated with the existing system is a random quantity which varies from hour to hour. Hence, the amount of energy generated by the incremental 1 megawatt generator illustrated in Figure 6-2 is itself a random quantity. Clearly, then, the appropriate question is what is the expected quantity of energy generated by the incremental unit. 
Assume that the expected quantity of energy produced by the 1 megawatt unit is $y$ megawatt-hours/year and the total annualized cost of the additional unit is $A$. If $v$ is the dollar value per megawatt-hour of unserved electrical energy, then Telson argues that $A$ and vy should not be orders of magnitude apart. However, Telson sugges ts that reliability levels typically are chosen such that $A \gg v y$ and, in particular, if LOLP is chosen at "I day in ten years," then A may be several hundred times larger than vy. Although Telson does not advocate, for example, that one should set $A=v y$, he does suggest that reliability levels in the U.S. may be fixed at higher than justifiable levels. In any event, the methodology described by Telson for choosing an appropriate reliability level is a marginal comparison of A with vy. The determination of $A$ is routine and straightforward. However, the calculation of $y$ and, especially $v$, is far from routine. The determination of $y$ is basically a mathematical question while specifying $v$ is one of economics. For the latter question one must somehow put a "price" on how much consumers would be willing to pay to satisfy what would otherwise be unserved electrical demand. For example, should the "price", $v$, be related to a normal electric rate of, say, $5 \not$ per Kwh? This, of course, depends upon the consumer. The owners of a refrigerated meat-packing plant or computer facility would view the question in an entirely different fashion than a residentlal homeowner with an electric water heater. Aithough it seems clear thal the consumer weighted $v$ should be significantly larger than $5 \$ / \mathrm{kwh}$, how much larger is by no means obvious. In fact there is an ever-growing 
literature devoted to both theory and empiricism concerning the estimation of $v$. One method suggested by Telson is to calculate, for a given region, the ratio of total salaries and wages of the labor force divided by the electrical energy consumption in the industrial and commercial sectors. According to Telson [34] this ratio for the State of New York was $\$ 1.223 / \mathrm{Kwh}$ in 1970 and for the nation as a whole the ratio was $\$ .574 / \mathrm{Kwh}$ in 1970 . (For alternative estimates, see Crew and Kleindorfer [10], Munasinghe and Gellerson [22] and Webb [36].)

The formal determination of $y$ is a straightforward, although somewhat laborious, calculation. Telson suggests the use of an approximation that greatly simplifies the estimation process. The approximation results in estimating $y$ by

$$
y \doteq p H(L O L P)
$$

where

$$
\begin{aligned}
p & \equiv \text { availability of marginal generator } \\
H & \equiv \text { number of hours in time period } \\
\text { LOLP } & =\text { loss of Load Probability }
\end{aligned}
$$

For example, if $p=.9, H=8760$ and LOLP $=.1$ days $/$ year $=2.4$ hours $/$ 8760 hours, then

$$
y \doteq 2.16 \text { mwhrs/year. }
$$

Hence, if one assumed that 2.16 mwhrs/year of unserved electrical energy would be satisfied by the 1 megawatt generator for each of the next 25 years, then the present value of additional mwhrs generated would be 


$$
\sum_{t=1}^{25} \frac{2.16}{(1+i)^{t}}=16.56 \text { mwhrs }
$$

where $i=.15$ is used as the discount factor. So, if one mwhr is valued at $\$ 1223$ (and then multiplied by 2 to roughly account for inflation), then the present value to consumers of an additional 1 megawatt generator is

$$
16.56 \times 2446=\$ 40,505 .
$$

But, since a 1 megawatt generator (peaking turbine) costs at least $\$ 200,000$ to $\$ 300,000$ (not even, considering the associated fuel costs), Telson argues that an LOLP of .1 days/year is too high. Telson suggests .. . the present "l day in 10 years" loss of load probability target reliability planning criterion may be uneconomically high and these targets might reasonably be reduced to at least " 5 days in 10 years" level.

Telson's recommendation appears less radical when one is reminded that the quality of service perceived by and influencing most residential consumers is mainly a function of the distribution network as contrasted with the reliability of the actual generators. Telson says . . only a handful of the loss of load incidents reported under FPC Order 331-1 had been a result of insufficient generating capacity, as contrasted to distribution or transmission system failures.

However, it should be emphasized that policy conclusions based upon this methodology are highly sensitive to the choice of $v$. For example, Munasinghe and Gellerson [22] estimate the industrial value of $v$ at levels of three- or fourfold higher than Telson's aggregate of $\$ 2446 /$ Mwh (in 1980 dollars). In contrast to Telson such values of $v$ clearly support the current posture of very high bulk power system reliability. 


\section{Chapter 7}

\section{Probabilistic Reliability Standards and Capacity Expansion}

This chapter reports on recent work by Bloom ([ 4$],[5]$, $[6])$ and others directed toward the explicit incorporation of reliability standards into the mathematical programming based model of Masse and Gibrat [21]. (This Masse and Gibrat model is described in Chapter 2). The motivating idea is that reliability constraints may not be adequately represented by the generation reserve margin constraint (2-5) which, for convenience, is repeated below:

$$
\sum_{j=1}^{J} \sum_{v=-v}^{t} a_{j v} x_{j v} \geq(1+m) \hat{Q}_{t} \quad t=1,2, \ldots, T
$$

where $a_{j v}$ is the availability of plant $j$ and vintage $v, m$ is the reserve margin, and $\hat{Q}_{t}$ is the expected peak load. Constraint (7-1) simply ensures that aggregate capacity is maintained at a level of $m$ percent larger than expected peak demands.

The validity of (7-1) to represent reliability standards in the capacity expansion model presumably would depend upon the level of aggregation, i.e., whether the model $(2-6)$ is used to represent a single utility or some aggregate of utilities which may span several states. The fact is that typical bulk system generating reliability indices (see [7], [37]) such as Loss of Load Probability and Expected Unserved Energy are almost always determined and restricted to the domain spanned by the utility's own generators. It is current practice (see [7]) for a given utility not to include interties with other 
utilities in the computation of its bulk system generation reliability. Hence, it may be unrealistic to constrain capacity expansion planning alternatives of a large aggregate region by a reliability standard which apparently is not used. On the other hand, however, reliability standards most definitely affect capacity expansion plans of a particular utility. For some utilities the reliability standard is, in fact, simply a reserve margin constraint such as (7-1). But in a recent study Billinton [7] reported that probabilistically based criteria are commonplace for larger utilities. Hence, for applications of the Masse and Gibrat capacity expansion model for planning by a given utility, a good deal more realism may be obtained by replacing the rather crude reserve margin constraint (7-1) with a more realistic reliability criterion. How this can be done is described below. The reliability criterion considered in Bloom [4] is Expected Unserved Energy (EUE). Unserved energy occurs during an interval of time whenever the load exceeds the available capacity. Unserved energy in a particular time period is a random variable since, due to forced outages, available capacity is random. For example, if the load during some given hour is 100 megawatts and the available capacity takes on values 110,100 and 90 with probabilities $.8, .15$ and .05 , respectively, the EUE is 


$$
\begin{aligned}
& (100-110) \mathrm{mw} \times 1 \mathrm{hr} \times 0=0 \\
& (100-100) \mathrm{mw} \times 1 \mathrm{hr} \times 0=0 \\
& (100-90) \mathrm{mw} \times 1 \mathrm{hr} \times .05=.5
\end{aligned}
$$

.5 megawatt hours

Hence, in this hour one expects to incur .5 megawatt hours of unserved energy. If one restricts EUE to be less than :2 for this hour, then some additional capacity would be required.

In practice one does not attempt to control EUE in each and every hour of the year: Instead one usually specifies a yearly total, say $\overline{E U E}$ and attempts to specify investment and operating policy so that

$$
\mathrm{EUE}_{\mathrm{t}} \leq \overline{\mathrm{EUE}}_{\mathrm{t}} \quad \mathrm{t}=1,2, \ldots, \mathrm{T}
$$

where $E U E_{t}$ is a rather complicated nonlinear function of the decision variables. Conceptually, though, a calculation such as (7-2) could be done for each hour in period $t$ and then summed over all hours to obtain $E_{U E}$. Since this rhapter addresses only the conceptual issues, more elegant and sophisticated means of calculating EUEt are not of interest. It suffices to conclude that EUE $t$ is a complicated, nonlinear function of the decision variables and the assumed loadduration curve.

The most straightforward statement of the capacity expansion problem incorporating explicit constraints on $E_{U} E_{t}$ is obtained when $(7-1)$ is replaced by $(7-3)$ in the model $(2-6)$, 


$$
\begin{aligned}
& \min \sum_{v=1}^{T} \sum_{j=1}^{J} c_{j v} x_{j v}+\sum_{j=1}^{J} \sum_{t=1}^{T} \sum_{v=-v}^{+} \sum_{p=1}^{p} \theta_{t p} f_{j t v p} u_{j t v p} \\
& \begin{array}{ll}
\sum_{j=1}^{J} \sum_{v=-v}^{t} u_{j t v p} \geq Q_{t p} & t=1,2, \ldots, T \\
p=1,2, \ldots, P
\end{array} \\
& 0 \leq u_{j t v p} \leq a_{j v} x_{j v} \quad j=1,2, \ldots \ldots, J \\
& v=-v, \ldots . ., t \\
& t=1,2, \ldots ., T \\
& p=1,2, \ldots, p \\
& \mathrm{EUE}_{t} \leq \overline{\mathrm{EUE}}_{t} \quad \mathrm{t}=1,2, \ldots . \mathrm{T} \\
& x_{j v} \geq 0, \quad j=1,2, \ldots ., T \\
& v=-v, \ldots . ., t
\end{aligned}
$$

where, again, EUE $t$ is a complicated, nonlinear function of the decision variables. It should be emphasized, however, that the present symbolic treatment of the EUE constraint (7-7) masks a subtle, but important inconsistency in the present notation. On the one hand the variables $\left\{u_{j t v p}\right\}$ are treated as deterministic quantities in $(7-4),(7-5)$ and $(7-6)$, while in (7-7) at least one quantity must be random (since expected values are involved). The quantities considered random in the computation of EUEt are, due to forced-outages, the levels of $\left\{u_{j t v p}\right\}$. The formulations by Bloom and others avoid some of these apparent complications by explicitly working with expected values. which, in turn, require sequentially convolving a set of probability distributions.' Such approaches are more algorithmic than conceptually oriented. For this reason the 
basic model and results of Bloom [4], [5] and [6] are presented in a slightly different framework. The main idea, however, remains the decomposition of the overall problem into two problems, a deterministic investment model and a stochastic production sub-problem.

The solution strategy advocated by Bloom for (7-4), (7-5), (7-6) and (7-7) consists of a Benders-type decomposition procedure. One creates a master program in which only the investment variables $\left\{\bar{x}_{j v}\right\}$ are determined. This master program is an ordinary linear program which is a type of relaxation of (7-4), (7-5), (7-6) and (7-7), e.g., the reliability constraints are not included in the master program. Given a trial set of investment values $\left\{\bar{x}_{j v}\right\}$ one then formulates $T$ different sub-problems, $t=1,2, \ldots, T$, where a typical sub-problem for period $\bar{t}$ is

$$
\begin{aligned}
& \min E\left\{0 \text { perating } \operatorname{Cos} t_{\bar{t}}\right\} \\
& \text { EUE } \bar{t} \leq \overline{\mathrm{EUE}}_{\mathrm{t}} \\
& n \leq{ }^{j E V p} \leq a_{j v} \bar{x}_{j v} \quad j=1,2, \ldots . . J \\
& v=-v, \ldots, \bar{t} \\
& p=1,2, \ldots, p
\end{aligned}
$$

Several important points concerning the sub-problem must be highlighted:

(1) The question of whether the decision variables $\left\{u_{j \in v p}\right\}$ are stochastic or deterministic, again, appears unresolved. 
However, if the sub-problem is viewed as a two-stage program, then its interpretation becomes more clear. One first chooses decision quantities $\left\{u_{j{ }_{v p}}\right\}$ as the nominal power output from plant $j$, vintage $v$, and segment $p$ in time period $\bar{t}$. Due to forced outages, however, the actual power output, say $\hat{u}_{j E v p}$, will be less than or equal to $u_{\text {jtvp }}$. The expected operating cost $(7-8)$ is then

$$
\sum_{j=1}^{j} \sum_{v=-v}^{\bar{t}} \sum_{p=1}^{p} \theta_{\bar{t} p} f_{j \bar{t} v p} E\left[\dot{\hat{u}}_{j \overline{\operatorname{t}} v p}\right]
$$

and the expectation implied in (7-9) is also with respect to the random variables $\left\{u_{j E v p}\right\}$.

(2) It would appear that the sub-problem should also include the set of constraints (7-5) from the master program which ensure that supply exceeds demand at least during each sub-interval of time $p$, i.e.,

$$
\sum_{j=1}^{j} \sum_{v=-v}^{\bar{t}} u_{j E v p} \geq Q_{t p} \quad p=1,2, \ldots ., p
$$

However, in view of the stochastic considerations in (1) it would seem that one should specify "chance constraints"

$P\left[\sum_{j=1}^{j} \sum_{v=-v}^{\bar{t}} \hat{u}_{j E_{v p}} \geq Q_{E p}\right] \geq \alpha_{\bar{t}} p=1,2, \ldots, p$

or, alternatively, "expected-value" constraints

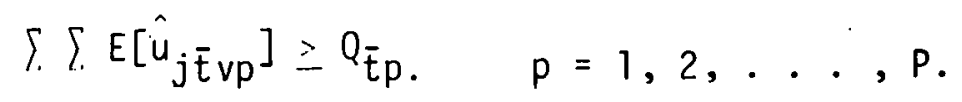


One reason this is not done in the sub-problem is that (7-11) and (7-12) are alternative measures of reliability. Furthermore, even if (7-12) is included in the subproblem, in most all cases the single constraint (7-9) apparently would make the constraints $(7-12)$ redundant. Relationships between (7-9) and (7-12) have not been discussed in the literature.

(3) It is very important to note that the sub-problem (7-8), (7-9) and (7-10) is trivial to solve. Given a set of fixed capacities, the expected operating cost is minimized by dispatching the generators in the ordinary merit order sequence. Units must be dispatched until

$$
E U E_{\bar{t}}=\overline{E U E} \bar{t} \text {. }
$$

or until no units remain,

$$
E U E_{\bar{t}}<\overline{E U E} \bar{t}
$$

in which case the sub-problem is infeasible. (There is an important assumption here that a megawatt of capacity type $x$ increments $E E_{\bar{t}}$ at the same rate as a megawatt of any other caparity y).

In summary, a characterization of the decomposition strategy is given by Bloom [4]: 
In the decomposition approach, trial values for the optimal generation expansion plan are determined by solving a linear program called the master problem. The production cost and reliability of this trial plan are determined in a set of subproblems. . . . Also calculated in the subproblem are dual multipliers, which give the changes in production cost and reliability due to marginal changes in the trial plant capacities. These dual multipliers are used to modify the master problem, which is then re-solved to determine a new trial expansion plan. The process continues, alternately solving the master problem and the subproblems, until an optimal expansion plan has been found. 
Chapter 8

The Averch-Johnson Hypothes is

Under Uncertainty

Overview

The Averch-Johnson hypothesis concerns the behavior of a monopoly subject to regulation based upon allowed rate of return on capital investment. The main assertion of the hypothesis is that such regulation leads to inefficient production systems since capital/labor tradeoffs become biased toward capital, i.e., capital is substituted for labor (and fuel, etc.) to enlarge the rate base. Since the conjecture was first suggested by Harvey Averch and Leland Johnson [3] in 1962, there has been a continuing controversy concerning both the validity and empirical measurement of the soCalled A-J effect. However, most of this literature has presumed that parameters such as price, factor costs and production technology are known deterministically. (A review of this literature is included in the earlier reports of this project; see [28] and [29]). Consideration of the A-J effect under uncertainty has occurred only recently and one of the more important contributions is by Peles and Stein [25]. Peles and Stein show that under a certain type of uncertainty there exists an "anti A-J effect." The two types of uncertainty (which are subsequently defined) are the "additive" and "multiplicative" types. In the case of the multiplicative type uncertainty, Peles and Stein prove the remarkable result that regulation leads to the use of less capital than would 
be employed by the same unregulated firm. This result is basically opposite of the classical conclusion which is derived in a deterministic framework, i.e., the result that regulation leads to the use of more capital than would be employed by the same unregulated firm.

The remainder of this chapter provides a review of the work of Peles and Stein [25] and is divided into three sections. The first section discusses the behavioral objectives of the firm subject to uncertainty, along with a descritpion of the assumed two-stage decision process. Following this section is a discussion about the incorporation of the regulatory constraint into the decision framework. Finally, the "anti A-J theorem" is presented.

\section{Behavior of the Firm Under Uncertainty}

In describing the motivation for incorporating uncertainty into the standard A-J analysis, Peles and Stein note:

When the firm decides upon its optimal scale of plant, the total revenue function expected to prevail when the plant is in operation is not known with certainty. A firm does not know precisely what will: be the growth of demand, the geographic location of its cus tomers, or the development of rival technologies by firms which produce substitute products. If the proposed plant scale involves the introduction of a new techrology, then the firm is not even sure what will be the rate of output associated with a given vector of inputs. Uncertainty in this context refers to the state of nature, described by variable $u$, that prevails when the plant is in operation.

The formal manner in which uncertainty is incorporated by Peles and Stein into the A-J framework is by assuming that price, 
$p$, depends not only upon quantity, $Q$, but also upon the state of nature, $u$ :

$$
p=f(Q, u)
$$

Hence, revenue, $R$, can be written

$$
R=P Q=H(Q, u) \text {, }
$$

where

$$
Q=\phi(K, L)
$$

is the production function with input factors of capital, $K$, and labor, L: Substituting for $Q$ in (8-2) yields

$$
R=H(K, L, u)
$$

so that (random) profit $Z$ is

$$
Z=H(K, L, U)-i K-w L \text {, }
$$

where $i$ is the cost of capital and $w$ the cost of labor. (Profit is random in (8-4) since it depends explicitly on the random variabre u.)

Now suppose that the decision process is of the two-stage type $i$, which one first chooses capital stock $K$, and then chooses $L$ only after $u$ is observed. In other words choose $k$, observe $u$, and then choose L. In this context one could proceed in a fashion that is similar to the "wait and see" strategy of stochastic programming. 
70

For each possible pair of $K$ and $u$ let $\hat{L}(K, u)$ be the level of labor that maximizes (8-4). By substituting $\hat{L}$ into (8-4) a function

$$
Z=R(K, u)-i K
$$

can be determined which represents expected net profit given that one first chooses $K$ and then observes state of nature $u$. Pales and Stein call (8-5) the "quasi rents" function.

Now assume that $u$ is fixed at some particular value, say $\vec{u}$, and consider the graph of $R(K, \bar{u})$ versus $K$ shown in Figure 8-1.

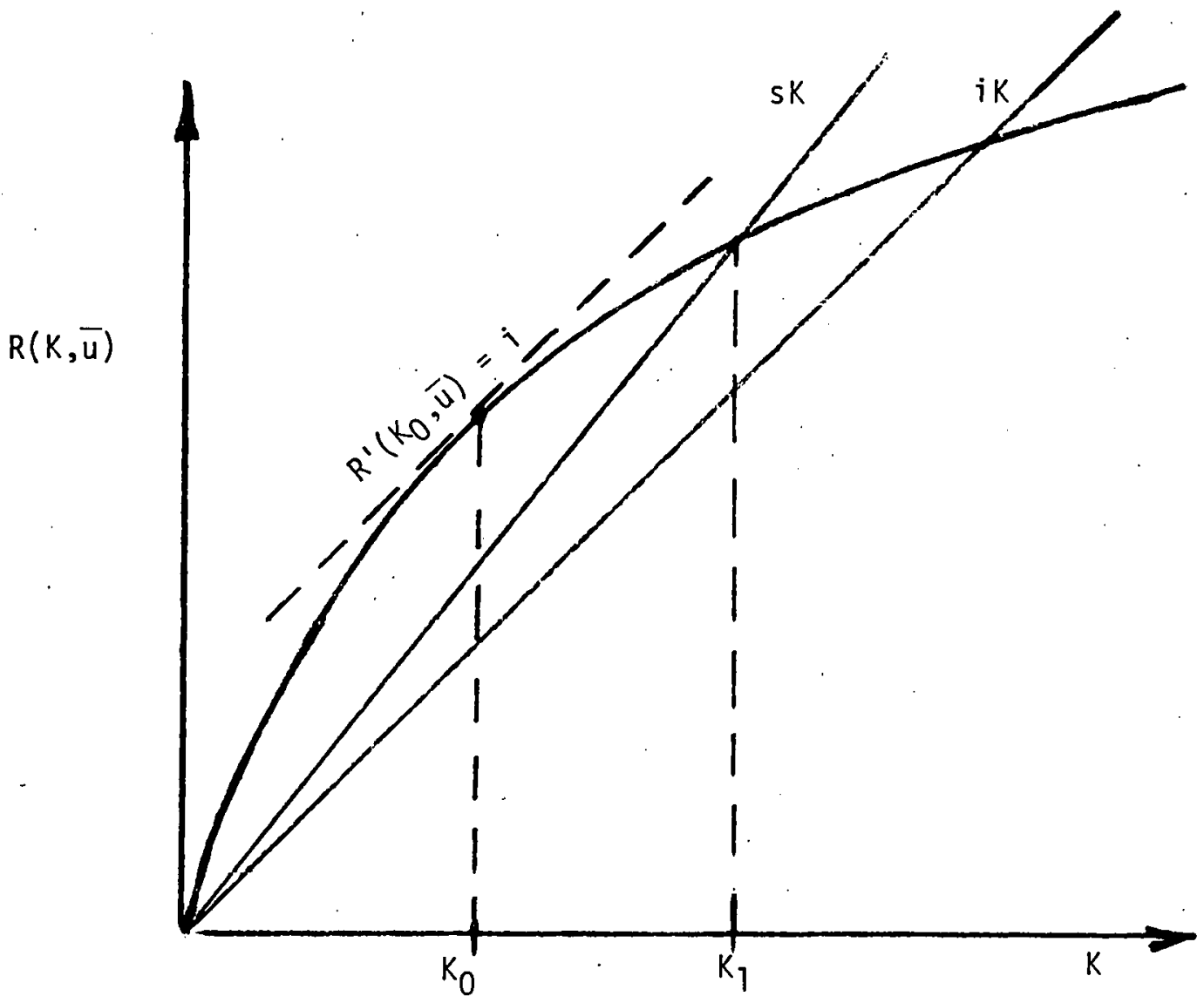

Figure $8-1$

Classical A-J Analysis 
Figure 8-1 illustrates the classical A-J result. The optimal level of capital of the unregulated firm, $K_{0}$, is determined at the point that maximizes $(8-5)$, i.e., where $R^{\prime}\left(K_{0}, \bar{u}\right)=i$. If $s$ is the allowed rate of return, then for $s$ close enough to $i$, the effect of regulation is to increase the use of capital to $k_{1}$. However, the "antiA-J theorem" will show just the oppositite. Under the multiplicative type of uncertainty the effect of regulation is to reduce the use of capital below $k_{0}$ when the allowed rate of return $s$ becomes close to the cost of capital i.

The two important special cases of $R(K, u)$ analyzed by Peles and Ste in are

$$
R(K, u)=R(K)+u
$$

and

$$
R(K, u)=R(K)(1+u)
$$

called additive and multiplicative uncertainty, respectively. The anti $A=J$ theorem applies to multiplicative uncertainty. It. is assumed that $E(u)=0$ so that in both cases

$$
E\{R(K, u)\}=R(K) .
$$

The usual objective of the unregulated firm is to maximize the utility of expected profits: 


$$
\max _{K} U[E\{R(K, u)\}-i K] .
$$

For the case in which the firm is risk neutral, i.e., $U(\cdot)$ is linear, it follows that the objective of the unregulated firm is

$$
\max _{K} R(K)-i K .
$$

Hence, the optimal ex ante choice of capital for the risk-neutral; unregulated firm subject to uncertainty is not only independent of the particular type of uncertainty, the level of capital chosen is independent of uncertainty. (As shown by Sandmo [26], Leland [19] and others this is not true for risk-averse firms, i.e., firms for which the utility function is concave.)

\section{The Regulatory Constraint and Expected Profits}

The implied mathematical form of the Peles and Stein stochastic extension of the classical A-J deterministic model (assuming a risk-neutral firm) is

$$
\begin{aligned}
& \max E\{R(K, u)\}-i K \\
& \text { s.t. } \\
& \quad E\{R(K, u)\}-s K \leq 0 \\
& \quad K \geq 0 .
\end{aligned}
$$

The basic reason that (8-9) is only implied, and not formally stated, is that Peles and Stein interpret (8-9) in a dynamic context. The dynamic context is to mean that sufficient time elapses so regulatory 
commissions can adjust price downward if excess profits temporarily. occur. In this case it is straightforward to show that the single constraint in (8-9) is redundant. Consequently, profits in the longrun never exceed $s K$, and hence the stochastic version of $A-J$ is simply

$$
\begin{aligned}
& \max E\{R(K, u)\}-i K \\
& K \geq 0 .
\end{aligned}
$$

The assumptions and explanations of how the constrained program (8-9) reduces to the unconstrained program (8-10) are discussed below.

For a given choice of $\bar{K}$ Peles and Stein partition the states of nature $u$ into two disjoint sets, namely

$$
S(\bar{K}) \equiv\{u \mid R(\bar{K}, u)<s \bar{K}\}
$$

and

$$
T(\bar{K}) \equiv\{u \mid R(\bar{K}, u) \geq s \bar{K}\}
$$

where

$$
P[u \varepsilon S(\bar{K})]+P[u \varepsilon T(\bar{K})]=i
$$

Suppose the state of nature $\bar{u}$ which occurs yields the revenue curve given in Figure 8-1 where $\bar{K}$ lies to the right of $k_{l}$, i.e., $\bar{K}>K_{1}$. For this $\bar{u}$ the realized profit (which is given by $R(\bar{K}, \bar{u})$ ) is clearly less than $s \bar{K}$. On the other hand if $\bar{K}$ had been chosen so that $\bar{k}<k_{1}$, then short-run profits would exceed the 
regulated maximum $s \bar{K}$. Nonetheless, after some regulatory lag price would be appropriately adjusted. Peles and Stein state:

Sooner or later, the regulatory authority would catch up with the firm and require it to lower price. . . . At the lower price, the quantity demanded would rise.... To produce the greater quantity demanded, more variable inputs (labor) would have to be employed. . . . When employment increases to satisfy demand the greater quantity demanded at the lower price, the marginal revenue product of labor is driven down below the wage. The regulatory authority will require the firm to lower $i$ ts price and meet the quantity demanded until quasi rents fall into $s \bar{k}, \ldots$ Hence, whe ther $\bar{u} \varepsilon S(\bar{K})$ or $\bar{u} \varepsilon T(\bar{K})$ it follows that realized profits (at least in the long run) are less than equal to $s \bar{K}$. It is then clear that

$$
E\{R(\bar{K}, u)\} \leq s \bar{K} ;
$$

furthermore, if $P[u \in T(\bar{K})]>0$, then the inequality in (8-11) is a strict inequality. Finally, since (8-11) holds for any ex ante choice of capital, $\bar{K}$, the equivalence of $(8-9)$ and $(8-10)$ is verified.

\section{The Anti A-1] Theorem}

In this section it is shown that multiplicative type uncertainty leads to a choice of capital that is actually less than the level that would be chosen by the unregulated firm. However, following Peles and Stein, it is first shown that the additive type uncertainty results in an optimal choice of capital that exceeds that of the unregulated firm. In the latter case, then, uncertainty leads to the same general over-capitalization that characterizes the deterministic model. 
For the additive case

$$
\begin{aligned}
E\{R(K, u)\}= & \int_{u \in S(K)}[R(K)+u] g(u) d u \\
& +s K \int_{u \in T(K)} g(u) d u
\end{aligned}
$$

so that

$$
\begin{aligned}
E\{R(K, u)\}= & R(K) P[u E S(K)]+\int_{u \in S(K)} u g(u) d u \\
& +\operatorname{sKP}[u E T(K)]
\end{aligned}
$$

where $g(\cdot)$ is the density function of $u$. If $\pi_{j}(K)$ represents expected net profit, then

$$
\begin{aligned}
\pi_{1}(K)= & E\{R(K, u)\}-i K \\
= & {[R(K)-s K] p[u \in S(K)] } \\
& +(s-i) K+E\{u \mid u \in S(K)\} .
\end{aligned}
$$

Next, differentiate (8-13) with respect to $K$ and neglect the derivatives of $P[u \varepsilon S(K)]$ and $E\{u \mid u \varepsilon S(K)\}$; the result is

$$
\pi_{1}^{\prime}(K)=\left[R^{\prime}(K)-s\right] P[u \varepsilon S(K)]-(i-s) .
$$

If $K_{0}$ represents the capital choice for the unregulated firm, then $R^{\prime}\left(K_{0}\right)=i$ so that

$$
\pi j\left(k_{0}\right)=(s-i) P\left[u_{\varepsilon} T\left(k_{0}\right)\right]>0 .
$$


From (8-15) Peles and Stein noted:

It follows that total expected profits can be increased by selecting ex-ante a scale of plant larger than that chosen by the unregulated monopolist.

For the case of multiplicative type uncertainty

$$
E\{R(K, u)\}=E\{R(K)(1+u)\}
$$

so that

$$
\begin{aligned}
E\{R(K, u)\}= & \int_{u \varepsilon S(K)} R(K)(1+u) g(u) d u \\
& +\operatorname{sKP}\{u \varepsilon T(K)\}
\end{aligned}
$$

Let $\pi_{2}(K)$ be the expected profits under multiplicative uncertainty so that

$$
\begin{aligned}
\pi_{2}(K)= & E\{R(K, u)\}-i K \\
= & {[R(K)-s K] P[u \varepsilon S(K)] } \\
& +(s-i) K+E\{u \mid u \varepsilon S(K)\} R(K)
\end{aligned}
$$

Again, differentiate $\pi_{2}(K)$ with respect to $K$, but disregard the derivatives of $P[u \varepsilon S(K)]$ and $E\{u \mid u \varepsilon S(K)\}$. One obtains

$$
\begin{aligned}
\pi_{2}^{\prime}(K)= & {\left[R^{\prime}(K)-s\right] P[u \in S(K)]+(s-i) } \\
& +R^{\prime}(K) E\{u \mid u \in S(K)\},
\end{aligned}
$$

and substituting $K=K_{0}$, the optimal level of the unregulated firm, yields 


$$
\begin{aligned}
\pi_{2}^{\prime}\left(k_{0}\right)= & (s-i) P\left[u \in T\left(k_{0}\right)\right] \\
& +i E\left\{u \mid u \in S\left(K_{0}\right)\right\} .
\end{aligned}
$$

An important term to analyze in (8-19) is $E\left\{u \mid u \in S\left(K_{0}\right)\right\}$. If $u \in S\left(K_{0}\right)$ then by construction $R\left(K_{0}, u\right)<s K_{0}$. Since $R\left(K_{0}, u\right)=R\left(K_{0}\right)(1+u)$ it must then follow that $u<0$. Hence

$$
E\left\{u \mid u \varepsilon S\left(k_{0}\right)\right\}=\gamma<0 .
$$

Substituting (8-20) into (8-19) yields

$$
\pi_{2}^{\prime}\left(k_{0}\right)=(s-i) P\left[u \in T\left(k_{0}\right)\right]+i r
$$

The key observation in (8-21) is that as $s$ becomes close enough to $i,{ }_{2}^{\prime}\left(k_{0}\right)$ wi 11 become negative $($ since $i \gamma<0)$. Peles and Stein incidate

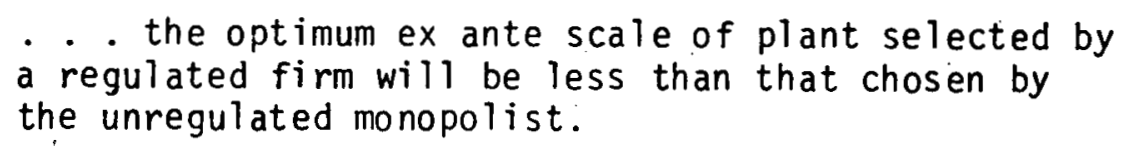


PART IV--INDUSTRY PRACTICE 
Chapter 9

Industry Implementation

of

Capacity Planning Models

\section{Overview}

This chapter deals with capacity planning models which have actually been implemented by a representative cross section of the electric utility industry. The number of such models is not large. In fact, just the opposite seems to be true. Few of the model types discussed in this report thus far can lay claim to a wide following. Undoubtedly one of the reasons for this apparent lack of implementation is the relative immaturity of such models. All the models described in Section III have been developed since 1976 and focus on some aspect of uncertainty. The reason for the new concern to incorporate uncertainty explicitly into the decision process is easily explained. Prior to the early 1970's the growth in demand, fuel costs and capital costs were stable and predictable. However, the Arab oil. embargo highlighted the arrival of a new era of uncertain demand, uncertain fuel costs, uncertain federal regulations and uncertain environmental concerns. Since the validation and assimilation process proceeds rather slowly, it will be sometime until it becomes clear which new approaches are adopted and which ones are not. Hence, a characteristic of capacity planning models currently in use is that most types of uncertainty are not explicitly taken into account. 
Another characteristic of contemporary capacity planning models used by the electric utility industry is so obvious it hardly seems necessary to mention. The models used by a particular utility company are specifically oriented and formulated to answer questions for that company. Should the company build a $400 \mathrm{mw}$ coal piant in 1985 and 1990 or an $850 \mathrm{mw}$ nuclear plant in 1988? That particular expansion policy is sought which minimizes the present value of all investment and operating expenditures. In other words, the client and ultimate user of the model is the utility itself. This model of the "firm" should be contrasted with "industry" models. An industry model is one which treats the totality of all electric utilities of some region in an aggregate form. Such a model may be constructed to answer questions such as what impact a stringent coal mining regulation will have upon the aggregate coal capacity in the South Atlantic states. Although Duke Power and Light Company of North Carolina is most assuredly interested in such questions, industry models are. developed and used by governmental planning and regulatory bodies rather than individual util1ty cumpdries.

Two models for capacity expansion planning of electric utilities which can lay claim to widespread usage are the Wein Automatic System Planning (WASP) model and the Optimized Generation Planning (OGP) model. Both these models which were developed in the early 1970's are oriented toward decision-making at the level of the firm. Furthermore, key inputs such as demand growth, fuel costs, capital costs, and 
regulatory decisions are assumed not to be subject to uncertainty. (However, both models reflect the traditional concern of maintaining adequate generating reliability; hence, uncertainty associated with the production system is an integral part of both models.) The WASP model was developed at the Tennessee Valley Authority (see [18]) and OGP was developed by General Electric Company [24]. Since over 100 utilities have at one time or another used at least one of these models, an understanding of WASP and OGP goes a long way toward characterizing the use of capacity planning models by the electric utility industry. Hence, the remainder of this chapter is devoted to the origins, backgrounds, assumptions, and operating characteristics of these two models.

The next section provides further background that helps explain why WASP and OGP have flourished and other approaches apparently have not. Next, the principal characteristics of WASP are described, and, finally, the differences between WASP and OGP are highlighted.

The Path to the Present

A broad overview of the main elements of capacity planning in the electric utility industry, as outlined in [32], is given below:
(1) Load Forecast
(?) Fxisting System
(3) Generation Reliability 
(4) Production Simulation

(5) Investment Anatysis

(6) Financial Analysis

(7) Judgemental Evaluation

The typical sequence of events that couple these elements together can be described, in a rough manner, as follows:

(a) A utility forecasts its expected load over the next $T$ years. This forecast, along with a detailed description of the existing generation types and sizes, comprise the initial conditions and basic framework for future capacity additions .

(b) By one means or another, a list of alternative expansion plans is determined. Each plan specifies the timing of a sequence of capacity additions (types and sizes).

(c) Each of the alternatives in (b) is subjected to analyses of types (3), (4) and (5). Generation Reliability acts as a constraint and eliminates those alternatives which do not gudranlee dn adequate supply of power. Production Simulation and Investment Analysis are used to determine the operational cost and investment cost, respectively, for each of the alternatives.

(d) The alternative plan which minimizes the total cost, while ensuring an adequate level of reliability, is then further analyzed from a financial point of view. For example, are 
the capital requirements attainable? Will cash flows be adequate? If the capital requirements, cash flows and other considerations are not realistic, then this alternative is either modified or removed from further consideration. Another alternative is advanced and subjected to the same financial considerations.

(e) The alternative, or set of alternatives, that are consistent with current and projected financial policies is subsequently subjected to a broad set of qualitative considerations. These include siting issues, regulatory concerns and environmental impacts. The ultimate choice of a capacity expansion alternative is then made considering both the economic and non-economic factors.

Although these steps broadly outline the capacity planning issues, it is, of course, naive to suppose that information and decision points are reached in such a regimented fashion. In general, information is looped back and forth among all the various elements of the expansion problem. Hence, the actual, process of arriving at a decision is not nearly as sequential as the previous discussion may seem to indicate. Furthermore, certain so-called judgemental factors may exert considerable influence in the "upstream" choice of a list of candidate expansion alternatives.

In [32] the importance of (3) Generation Reliability, (4)'Production Simulation and (5) Investment Analysis is emphasized as the 
"three principal analyses." These functions represent the heart of the engineering and economic appraisals of alternative plans. The following historical review is offered:

Al though the application of probability methods to ceneration reserve planning was described over forty years ago, it was not until the middle 1950's that the advent of the large scale digital computer made feasible the probability calculations of large generating systems. . . . As time went on, programs became quite automatic, producing expansion patterns to a specified reliability index and even sizing units to fit a given unit size policy. The second facet of generation planning-production cost simulation--also developed rapidly with digital computer technology. .. . As with the probability techniques, there has been continuous development to improve the accuracy and realism of the simulation of system operation. . . These two techniques, probability and production simulation, followed by the third procedure of investment costing have paced the development of the expansion of generation systems. . .

Both WASP and OGP are characterized as integrative methods incorporating the "three principal analyses." For example, Felak and Lapsa [12] note:

Historically, OGP evolved directly from the available base of maximally detailed free standing models that General Electric had previously authored for use by the utility industry. . . . models that addressed the critical questions raised by the processes of system reliability evaluation and production costing were adapted for use within OGP.

The major point is that both WASP and OGP are constructed by suitably piecing together smaller programs into a larger integrative framework. Each of these smaller programs address one specific element of the capacity planning problem. The larger integrative framework addresses the questions of

(1) generating the list of alternative expansion programs,

(2) choosing from this list the least cost alterantive. 
In [32] the situation is described as follows:

Regardless of the degree of sophistication attained by the three programs forementioned, generation planning remained a three-step, cut and try, iterative process; devise a mix and unit size plan of generation additions, time the unit additions in order to meet a specified reliability criterion, and calculate the associated costs of the power plant investment and operation: This process would be repeated over and over for many desired combinations of size and mix patterns. . . However, the process was so time consuming and costly that it was not feasible to investigate the effect of parameter variations in any real depth. This became a serious shortcoming as uncertainty about future conditions grew.

Comments like these have subsequentiy led to the development of "integrated methods" of capacity planning such as WASP and OGP. The integrated methods not on ly perform and automate the three principal analyses, but they add a new dimension. The integrated methods also generate the list of alternative expansion plans and subsequently make an optimal selection from the list. Hence, a description and characterization of both WASP and OGP should be logically divided into two parts. In the first part one describes the main assumptions and properties of the "three principal analyses," and in the second part one describes the "optimizing framework:" Since the first part has a Tready been addressed by an earlier report of this project (see [30]), only the second part, the optimizing framework, is presented in the next section.

Before preceding to the next section, however, a comment concerning reasons for the widespread usage of WASP and OGP is given. Felak and Lapsa [12] put it as follows: 
. . it is apparent that the probability and production costing routines of the OGP program have evolved from a history of accuracy and realism in these functions of generation planning. Th is is important when it comes to considering optimization methods, for, in the final analys is, "optimum" means not only a specified minimum cost plan (the specification, of which incidentally, may be quite subtle), but minimum cost according to some method of calculation. The production cost and probability routines incorporated in an optimizing program are ordinarily the only means of testing the optimization. When, in the interests of theoretical or mathematical correctness, the optimization techniques of a program are made too complex, the planning calculations must be made too simple in order to conserve computer running time. It is quite possible to end up with a masterful optimization of the wrong objective function.

It appears that WASP and OGP have stood the test of time because their main components of system reliability and production costing can be independently corroborated and verified. This apparent validity on the production side must outweigh any gains associated with alternative models which incorporate more sophisticated optimizing methodologies.

\title{
The Optimizing Framework of WASP
}

The optimizing methodology of WASP is dynamic programming. The overall concept is illustrated in Figure $9=1$. The example exhibits a three period horizon; time $t=0$ represents the present time and the existing state is labelled state 1 . State 1 represents the current mix of generating capacity, e.g., state 1 could represent a current system of

\author{
$200 \mathrm{mw}$ coal \\ 100 mw nuclear \\ $50 \mathrm{mw} 011$.
}




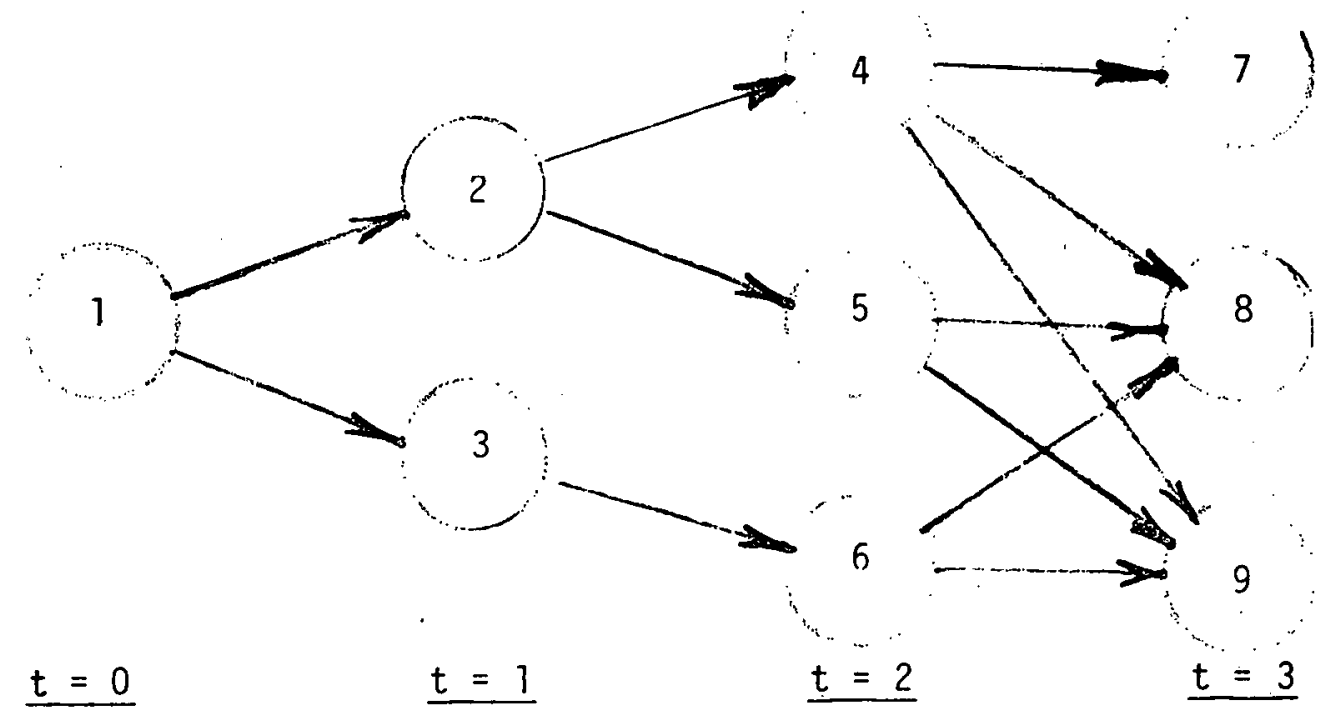

Figure 9-1

Three Period Dynamic Program

At time $t=1$ the system is allowed to be in either state 2 or state 3. For example, if state 2 and state 3 are defined as

\section{State 2}

$200 \mathrm{mw}$ coal

$150 \mathrm{mw}$ nuclear

$60 \mathrm{mw}$ oil
State 3

240 coal

$100 \mathrm{mw}$

70 oil

then in moving from time $t=0$ to $t=1$ one of two expansions must be chosen:

Choose State 2
Add 0 coal
Add 50 nuclear
- Add 10 oil

Choose State 2

Add 0 coal

Add 10 oil

\section{Choose State 3}

Add 40 coal

Add 0 nuclear

Add 20 oil 
In th is example no other alternatives are possible. Furthermore, if state 6 is defined by

\author{
State 6 \\ $260 \mathrm{coal}$ \\ 110 nuclear \\ 80 oil
}

then it is impossible to be in state 2 at $t=1$ and be in state 6 at $t=2$. Observe that such a transition would require moving from a state which contains $150 \mathrm{mw}$ of nuclear to a state with $110 \mathrm{mw}$ of nuclear. (In light of current events such a transition may be possible; however, in the WASP conceptual framework it cannot happen.) The definitions of the remaining states are made analogously.

The optimization in WASP is accomplished in three distinct phases:

(1) Define the stages and alternative states in each stage.

(2) Compute the production cost of each state.

(3) Find the least cost path from stage $t=0$ to stage $t=3$. The total cost is comprised of a production cost (associated with each node) and an investment cost (associated with each arc). Dynamic programming is applied to determine the least cost path from stage $t=0$ to stage $t=3$.

The fact is that WASP contains a separate program to perform each one of these three tasks. According to [18] these programs are 


\section{(1) Expansion Configuration Generator Program (CONGEN)}

The Expansion Configuration Generator Program gives the system planner the ability to direct the area of study to expansion configurations that he believes to be most economic. This can be accomplished by specifying minimum and maximum reserve requirements, thus constraining the system capacity. Any expansion configuration whose capacity would fall outside the reserve requirements would not be considered as a feasible state. Limits can also be placed on the minimum and maximum number of units of a particular expansion candidate that can be installed in any given year. The CONGEN program forms a list of all allowable system configurations (or states) for each year in the study.

\section{(2) Merge and Simulate Program (MERSIM)}

This program calculates the operating cost for each of the configurations generated by the CONGEN program. A Probabilistic Simulation Model is used to calculate the unit loadings and the system operating cost. The reliability of the generating system is also estimated by calculating the probability that the generating system will not be able to meet the system load and the probable amount of unserved energy. In addition to calculating the total operating cost, the MERSIM program calculates the cumulative expenditure. . .

\section{(3) Optimization Program (DYNPRO)}

The DYNPRO program uses a dynamic programming algorithm to determine the optimal system expansion policy from the states defined in the CONGEN program. All the economic calculations, including the escalation of fuel prices, penalty on foreign expenditures, and present-worth calculations, are performed in the program.

Although dynamic programming represents a keystone of WASP, the application of dynamic programming to generation capacity planning was conceptualized several years earlier. In 1966 Dale [11] discussed many of the apparent advantages of the dynamic programming methodology. In $h$ is synops is Dale stated: 
At any stage in the process of making these decisions the correct choice cannot be made without considering all possible decisions that might have been made during earlier stages and that might be made in future stages. The paper describes a dynamic-programming application to this particular problem, which by eliminating many alternatives during each stage or year of a long-range study period, reduces the number of possible choices to proportions that can be handled and evaluated by a medium-sized computer. . .

The dynamic programming approach was further analyzed in 1972 by

Oatman and Hamant [23] for the Dayton Power and Light Company.

Oatman and. Hamant defined what they termed the "study selector chart."

This chart was essentially the analogue to the WASP-CONGEN program for determining alternative expansion possibilities. In response to a question about the nature and use of the study selector chart, 0atman and Hamant replied:

Selecting alternative units to examine is not so much a matter of "engineering art" or "excellent engineering judgment" as it is a confrontation with the realities of an actual system operating in a world where the choices al ready are limited by lead time, fuel availability, pre-commitments, and financing requirements.

The methods used to specify the study selector chart are simple and any unit that can be represented by an investment cost and a heat-rate may be studied. An overall feel for a system may be obtained by running several studies pitting two or three alternative types against each other. For example, individual twenty year studies comparing base-load fossil vs. cyclic fossil, base-load vs. peaking and cyclic vs. peaking will run extremely fast and produce a relative ordering of patterns from all peaking to all base with common mixes in between which can be directiy compared even though they come from three different studies. The multiple run technique has proved to be extremely useful for many applications.

Further refinement can be obtained by choosing more detailed units for the initial years when actual units must be selected, and limiting the terminating alternatives to several representative types (i.e., Base, Cyclic, Nuclear, Peaking). Again we would point out that the alternatives are limited only by the user's ability or willingness to pay for the production cost studies, which he can estimate beforehand. 
It should be clear that the extent of the alternative number of states generated in each stage directly affects the relative optimality of the final result. The preceding comments by 0atman and Hamant attempt to minimize this concern. Similarly, in [18] one reads statements about WASP such as:

In this (CONGEN) program, the system planner can exercise his skill and judgement by controlling the states generated, and thereby prevent the computer from examining all sorts of absurd configurations.

The manner in which the system planner can exercise his judgement in WASP is by bounding both total and individual generation capacities. For example, in Figure 9-1 one might restrict the number of states for stage $t=2$ to those in which

$$
400 \leq \text { total capacity } \leq 500
$$

and

$$
\begin{aligned}
& 200 \leq \text { coal } \leq 300 \\
& 100 \leq \text { nuclear } \leq 175 \\
& 50 \leq 0 i 1 \leq 100 .
\end{aligned}
$$

As a final comment about the optimizing methodology of WASP, consider some contrasting methodologies. In a recent paper Sullivan and Claycombe [33] summarize some alternative methodologies as follows : 
Optimization procedures for the general problem under consideration can be placed in one of three categories. First, there are optimization methods based on large-scale linear programming models that unfortunately are not capable of dealing with economies (or diseconomies) of scale. Another general group of procedures utilize mixed-integer programming codes, and these procedures are able to deal with economies of scale in investment costs. However, the implied diseconomies of scale that are associated with reliability constraints present computational difficulties in this class of models. The third category of procedures for dealing with large-scale capacity expansion problems makes use of dynamic programming. These algorithms can account for most aspects of actual problems, but the amount of computation and data storage necessary has restricted analyses to relative short planning periods.

The WASP optimizing methodology is the latter alternative.

The Optimizing Framework of OGP

The basic designs of OGP and WASP are similar in that both provide a unifying framework for the "three principal analyses" of generation reliability, production simulation and investment analysis. However, the optimizing methodologies employed by each are quite different. In contrast to the dynamic programming framework of WASP, the methodology used in OGP is a myopic, year by year optimization. For example, the OGP methodology applied to Figure 9-1 would result in three sequential and separate optimizations. For period $t=1$, the OGP optimization is simply to choose between the two alternative states 2 and 3 , i.e., the optimization problem is to differentiate between the two alternative paths illustrated in Figure 9-2. The costs associated with each derision $A$ and $B$ are

(a) levelized annual investment costs,

(b) annual production costs. 


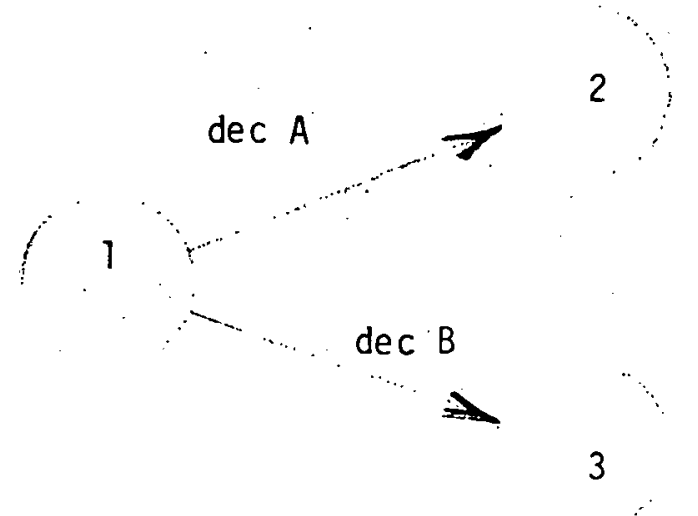

Figure 9-2

OGP Stage $t=0$ Decision

If the total annual costs for decision $A$ are lower, then the subsequent problem for stage $t=1$ is illustrated in Figure 9-3.

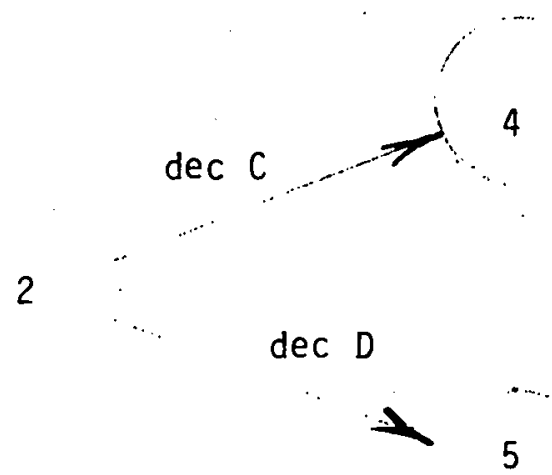

Figurè 9-3

OGP Stage $t=1$ Decision

In short, the OGP strategy is commonly referred to as a one period, rolling horizon strategy. However, the intended comparison between 
WASP and OGP utilizing Figures $9-1,9-2$ and $9-3$ is partly misleading. In OGP there is no reason why the possible states need to be identified a priori, and they need not be constrained to be small in number. The more appropriate graphic description of the OGP decision at stage $t=0$ is shown in Figure $9-4$.

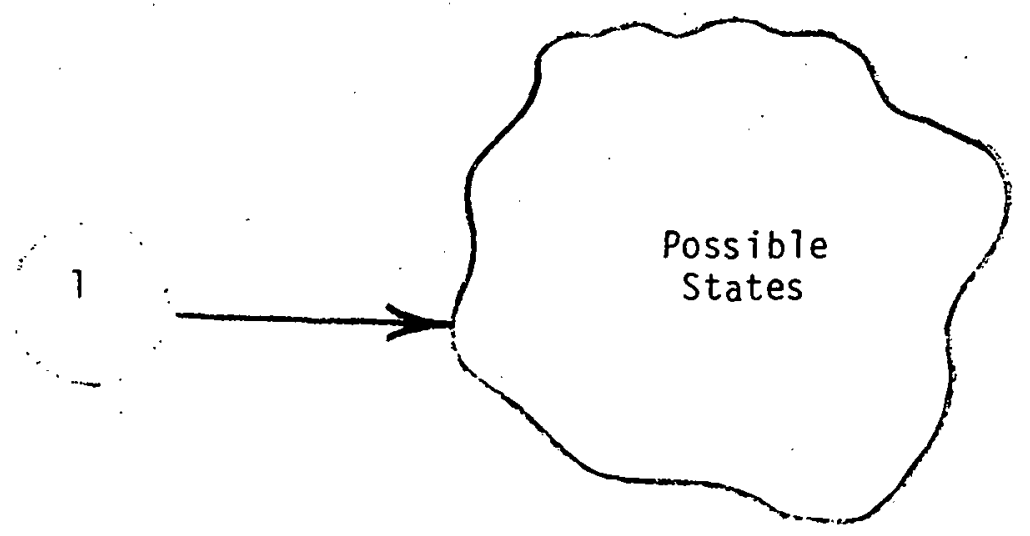

Figure 9-4

Revised OGP Decision at Stage $t=0$

The set of possible states in Figure $9-4$ can be as wide or restricted as one desires.

One complicating feature of the otherwise straightforward optimizing framework of OGP stems from the fact that the fuel costs and forced outage rates may not be constant throughout the life of a particular plant. How should the annual production costs be calculated and compared to other plant types when the relative fuel costs may be changing over time? Should one use the break-in forced outage rate or mature outage rates in conducting the production simulation? 
In OGP the resolution of these issues is to use those fuel costs and outage rates which are most representative of the system when in a steady-state operation. This is termed the "look ahead" strategy. In simplest terms it means that if data on two plant types are

\section{Present}

Future

Plant Type Fue ] Outage Rate Fue 1 Outage Rate

A $\mathrm{PF}_{\mathrm{A}}$ $\mathrm{POR}_{\mathrm{A}}$ $\mathrm{FF}_{\mathrm{A}}$ FORA B $P F_{B}$ PORB $\mathrm{FF}_{\mathrm{B}}$ FOR $\mathrm{R}_{\mathrm{B}}$

where $P$ represents the present, $F$ the steady-s tate future $\left(P F_{A}\right.$ is the present fuel cost for plant type $A$ and $\mathrm{POR}_{A}$ is the present outage rate for plant type $A$ ), then OGP uses the future values in the decision process. Lubbers [20] summarizes the OGP strategy as follows:

OGP's optimization is performed on a year-to-year basis: That is, the decision of which configurations to implement is made after computing the cost of the configurations corresponding to only one year in the planning period. In a pure year-to-year optimization, the decision of which new units to install would be made on the basis of one year's fixed charges and only one year's fuel costs. To avoid this problem, OGP uses a "look-ahead" period to weight the decisions for new generation, During this look-ahead, fuel costs are allowed to escalate at their predicted rates. Further, immature outage rates are applied within the look-ahead until new units reach a prescribed age.

As a final comment about the OGP methodology consider the contention of Felak and Lapsa that the myopic nature of OGP results in solutions unaffected by so-called "end-effects": 
An important by-product of the OGP optimization approach is, in general, a lack of end effects. For example, if two cases are executed which both have the same starting point in time and have no differences in input data except that the first OGP study is terminated after ten years, and the second after twenty, both will yield exactly the same results for the first ten years.

In conclusion then, WASP and OGP differ substantially in their respective optimizing frameworks. WASP is dynamic programming based and therefore represents an overall form of optimizing strategy, whereas OGP is a single year, rolling horizon optimization process. However, in a recent comparison in which both systems were run with similar input, Lubbers [20] reports:

The programs are shown to yield comparable results despite the different methodologies which they employ.

The fact is that both methods have been widely used because they apparently provide verifiable information about reliability, production costs and investment alternatives. 


\section{References}

[1] Anderson, D., "Modeis for Determining Least-Cost Investments in Electricity Supply," Bell J of Economics, Vol 3, No 1, Spring 1972 , pp 267-291.

[2] Arrow, K. J., "The Role of Securities in the Optimal Allocation of Risk Bearing," Review of Economic Studies, April 1964, pp $91-96$

[3] Averch, H.L., L.L. Johnson, "Behavior of the Firm Inder Regulatory Constraints," American Economic Review, Vol 52, 1962 , pp 10.52-1069.

[4] Bloom, J. A., "Optimal Generation Expansion Planning for Electric Utilities Using Decomposition and Probabilistic Simulation Techniques," Working paper OR 064-77, MIT, August 1977.

[5] Bloom, J. A., Decomposition and Probabilistic Simulation in Electric Utility Planning Models, Ph.D. Thesis, Department of Mathematics, June 1978.

[6] Bloom, J. A., "Long Range Generation Planning With Limited Energy and Storage Plants," TIMS-ORSA National Meeting, Wash.; D.C., May 1980.

[7] Billinton, R., "Reliability Criteria Used by Canadian Utilities in Generation Capacity Planning and Operation," IEEE Trans in PAS Vol PAS-97, May-June 1978, pp 931-939. 
[8] Cazalet, E. G., B. Judd, "Decision Analys is of California Electrical Capacity Expansion," SRI Project 5367, Stanford Research Institute, Menlo Park, Calif. (1977).

[9] Cazalet, E. G., C. E. Clark, T. W. Kellin, Costs and Benefits of Over/Under Capacity in Electric Power System Planning, EPRI Research Project 1107, Palo Alto, Calif. (1978).

[10] Crew, M. A., P. R. Kleindorfer, "Peak Load Pricing with a Diverse Technology," Bell J of Economics, Vol 7, No 1, Spring 1976, pp 207-231.

[11] Dale, K. M., "Dynamic Programming Approach to the Selection and Timing of Generation-plant Additions," Proceedings of IEE, Vol 113, No 5, May 1966.

[12] Felak, R. P., J. E. Lapsa, "General Electric's OGP Program: The Practical Approach to Generation Planning," EEI Engineering Computer Forum, Minneapolis, Minnesota (Sept 1978).

[13] Ford, A., A Dynamic Model of the United States Electric Utility Industry, Ph.D. Thes is, Dartmouth College, 1975.

[14] Forrester, J, Industrial Dynamics, MIT Press, Cambridge, Mass., 1961.

[15] Gilbert, R. J., J.E. Stiglitz, Effects of Ris.k on Prices and Quantities of Energy Supplies (Vol 2, Overview of the Economic Theory of Uncertainty and its Implications for Energy Supply) EPR̈L Kes Project 869-1, Palo Alto, Calif, May 1978. 
[16] Hartman, R., "Factor Demand with Output Price Uncertainty," American Economic Review, Vol 66, Sept 1976, pp 675-681.

[17] Holthausen, D. M., "Input Choices and Uncertain Demands," American Economic Review, Vol 66, March 1976, pp 94-103.

[18] Jenkins, R: T., D. S. Joy, "WEIN Automatic System Planning Package (WASP)--An Electric Utility Optimal Generation Expansion Code," Oak Ridge Nat'l Laboratory--Report 4945, Oak Ridge, Tenn. (July 1974).

[19] Leland, H., "Theory of the Firm Facing Uncertain Demand," American Economic Review, Vol 62, June 1972, pp 278-291.

[20] Lubbers, R. H., "WASP and OGP: A Comparison," EEI Engineering Computer Forum, Minneapolis, Minnesota (Sept 1978).

[21] Masse, P., R. Gibrat, "Application of Linear Programming to Investments in the Electric Power Industry," Management Science Vol 3, Jan 1957, pp 149-166.

[22]. Munasinghe, M., M. Gellerson, "Economic Criteria for Optimizing Power System Reliability Levels," Bell J of Economics, Vol 10, No 1, Spring 1979, pp 353-365.

[23] Oatman, E. N., L. J. Hamant, "A Dynamic Approach to Generation Expansion Planning," IEEE Trans on PAS, Vol PAS-93, Nov-Dec 1973, pp 1888-1896.

[24] "Optimized Generation Planning Program," General Electric Company, Schenectady, NY, Nov 1979. 
[25] Peles, Y. C., J. L. Stein, "The Effect of Rate of Return Regulation is Highly Sensitive to the Nature of the Uncertainty," American Economic Review, Vot 66, June 1976, pp 278-289.

[26] Sandmo, A., "On the Theory of the Competitive Firm Under Price Uncertainty," American Economic Review, Vol 61, March 1971, pp 65-73.

[27] Sanghvi, A. P., D. R. Limaye, "Planning for Electrical Generation Capacity in the Pacific Northwest: A Decision Analys is of the Costs of Over/Under Building," Journal of Energy Policy, Vol $4,1979$.

[28] Soyster, A. L., (Literature Survey for) "Project Independence Evaluation System Utility Model Validation," Dept. of Energy Project EI-78-R-01-6242 (Phase I), Systemetrics Inc., Blacksburg, Va., Dec 1978.

[29] Soyster, A. L., "Capacity Expansion Planning Under Uncertainty," Dept. of Energy Project EI-78-R-01-6242 (Phase II), Systemetrics Inc., Blacksburg, Va., March 1980.

[30] Soyster, A. 1., "Snme Observations on the Practice of Capacity Expansion in the Electric Utility Industry," Dept. of Energy Project EI-78-R-01-6242 (Phase II), Systemetrics Inc., Blacksburg, Va., May 1980 .

[31] Stover, J. G., W. Hayward, H. S. Becker, Incorporating Uncertainty in Energy Supply Mode 1s, EPRI Res- Project 1012-1, Palo Alto, Calif., Feb 1978. 
[32] Study of Benefits of Improved Power Plant Reliability and Productivity, Center for Energy Systems, General Electric Company, Wash., D.C., Sept 1977.

[33] Sullivan, W. G., W. Claycombe, "Decision Analys is of Capacity Expansion Strategies for Electrical Utilities," IEEE Tras on Eng Mgmt, Vol EM-24, No 4, Nov 1977, pp 139-144.

[34] Telson, M. L., "The Economics of Alternative Levels of Reliability for Electricity Generation System," Bell J of Economics, Vol 6, No 2, Autumn 1975, pp 679-694.

[35] Wagner, H. M., Principles of Operations Research, PrenticeHall, Englewood Clifss, NJ, 1969 .

[36] Webb, M., "The Determination of Reserve Generating Capacity Criteria in Electricity Supply," Applied Economics, March 1977, pp 19-31.

[37] Working Group on Performance Records for Optimizing System Design, "Reliability Indices for Use in Bulk Power Supply Adequacy Evaluation," IEEE Trans on PAS, Vol PAS-97, July-Aug 1978, pp 1097-1103. 